\title{
MEDELLÍN METROPOLITANA. \\ UNA APROXIMACIÓN A LA CIUDAD, LA CRISIS COMO OPORTUNIDAD
}

\author{
Jorge Pérez Jaramillo \\ Arquitecto, profesor asociado y decano entre 1993-2001 de la \\ Facultad de Arquitectura Universidad Pontificia Bolivariana de \\ Medellín. Actual director de la Facultad de Arquitectura y del \\ Instituto de Estudios Metropolitanos y Regionales de la misma \\ Universidad y profesor asociado de la Maestría en Arquitectu- \\ ra. Crítica y Proyecto.
}

Desde 1987 trabaja en diversos campos académicos y profesionales, programas y proyectos de Urbanismo y Arquitectura en Medellín Colombia, en diseño, gestión y procesos de planeación. Fue subdirector de Planeación del Arrea Metropolitana del Valle de Aburrá, Medellín, Colombia (2004-2008). Integró la Junta Técnica del Plan Estratégico para Medellín y el Valle de Aburrá 2015 (1998 - 1999) y la Sala Plena del Consejo Profesional de Arquitectura de Colombia (1998-2001).

Ha publicado en libros y medios especializados de Colombia, España, México, Alemania, Argentina y otros países, y ha participado como conferencista en diversos congresos, seminarios y cursos de arquitectura y urbanismo, entre los que se destacan la Bienal de Venecia Pabellón de Francia, TUDelft, Auburn University, Wentworth University, Universidad Central de Venezuela, Universidad de La Salle en México DF, TallerIGC, Congresos CIAL 2010 Rosario y Arquisur 2011 Resistencia y el Curso de Verano UIMP Santander España 2011.

jorgeperezjarmaillo.arquitecto@gmail.com; jorge.prezj@upb. edu.co; institutoiemr@gmail.com. 

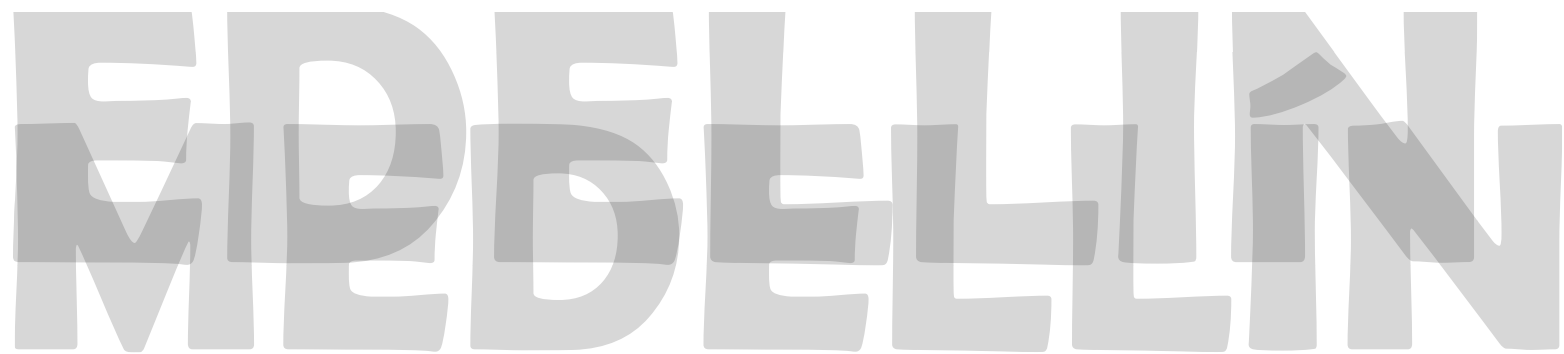

Este documento sintetiza un conjunto de presentaciones sobre Medellín, realizadas en Argentina a lo largo del año 2011, específicamente con ocasión del encuentro ARQUISUR en Resistencia. Texto construido a partir de una conferencia, documento-transcripción en asociación con Hans Schulz / Bariloche, Argentina, Crónicas, B2000. Medellín, mayo de 2012.

Presento el trabajo colectivo de nuestra gente, que entendió con especial fortaleza la trascendencia y exigencia del problema que enfrentamos durante las décadas de los años 80 y

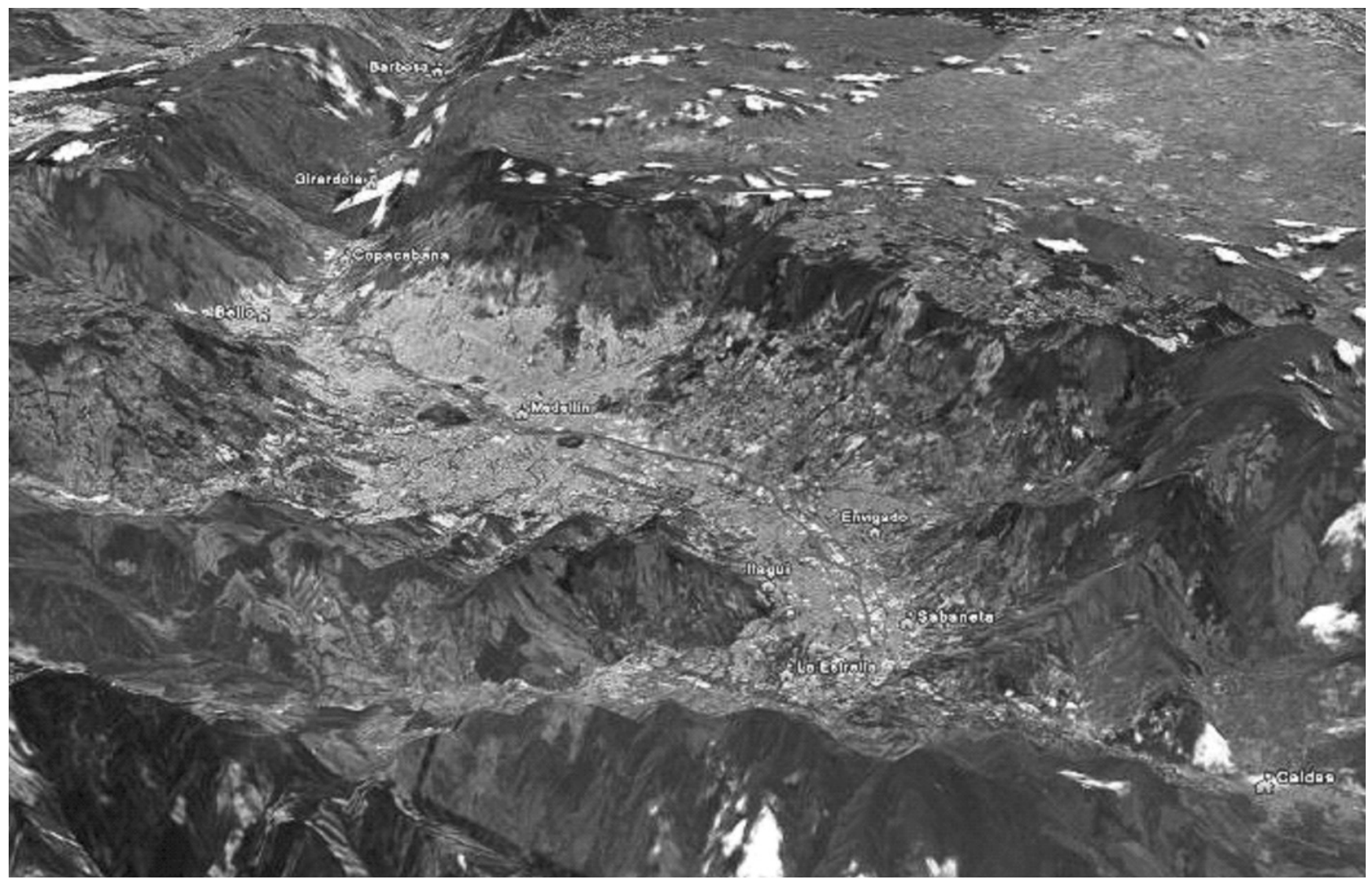



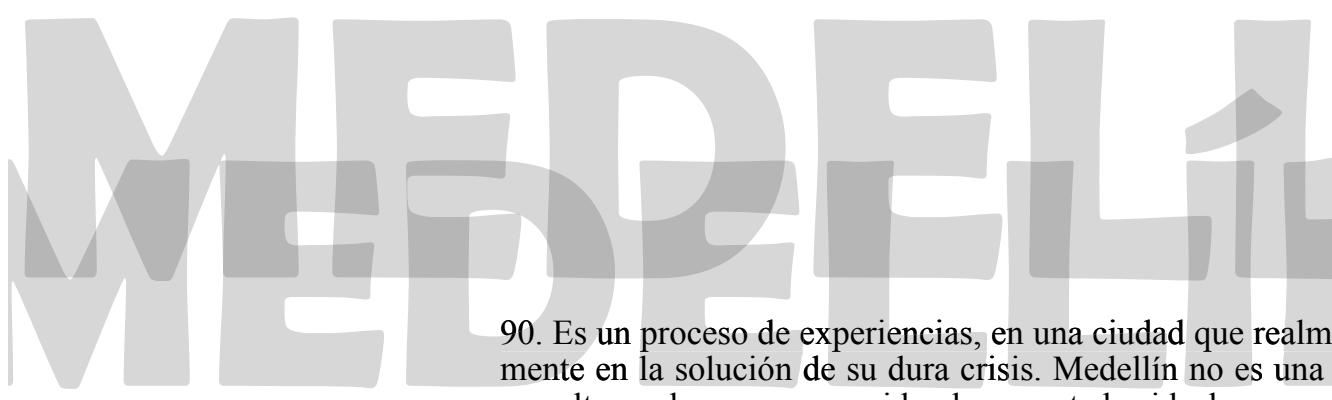

\section{Jorge Pérez Jaramillo}

90. Es un proceso de experiencias, en una ciudad que realmente ha avanzado sustancialmente en la solución de su dura crisis. Medellín no es una ciudad modelo ni tiene todo resuelto; no hemos conseguido plenamente los ideales que nos hemos propuesto. Nuestro camino es largo y complejo, pero sin duda hemos construido mucho a nivel social, político y físico durante los últimos años.

A lo largo de este documento, me refiero al contexto general, regional, territorial y político de la ciudad y explicaré el trabajo tanto a escala municipal como metropolitana, este último muy difícil pero muy exitoso, mediante la concertación entre todas las municipalidades de nuestra región metropolitana del Valle de Aburrá, esfuerzo que derivó en el Acuerdo Metropolitano N. ${ }^{\circ} 15$ de 2006 "Hacia una región de ciudades", un modelo territorial consensuado sobre un territorio amplio y complejo, tanto a nivel geográfico como político, social y cultural.

Refiero algunos de los múltiples proyectos ejecutados en el territorio, en desarrollo de la política urbana implementada en Medellín y la región.

Las obras de arquitectura y urbanismo representan la conclusión de un proceso social y político, que más que un sentido disciplinar estricto, expresan cómo el tejido de la ciudad se debe desarrollar entre políticas públicas, construcción social y ciudadana y gestión del

Medellín desde el cerro Nutibara hacia el oriente, desarrollo urbano.

Aburrá.

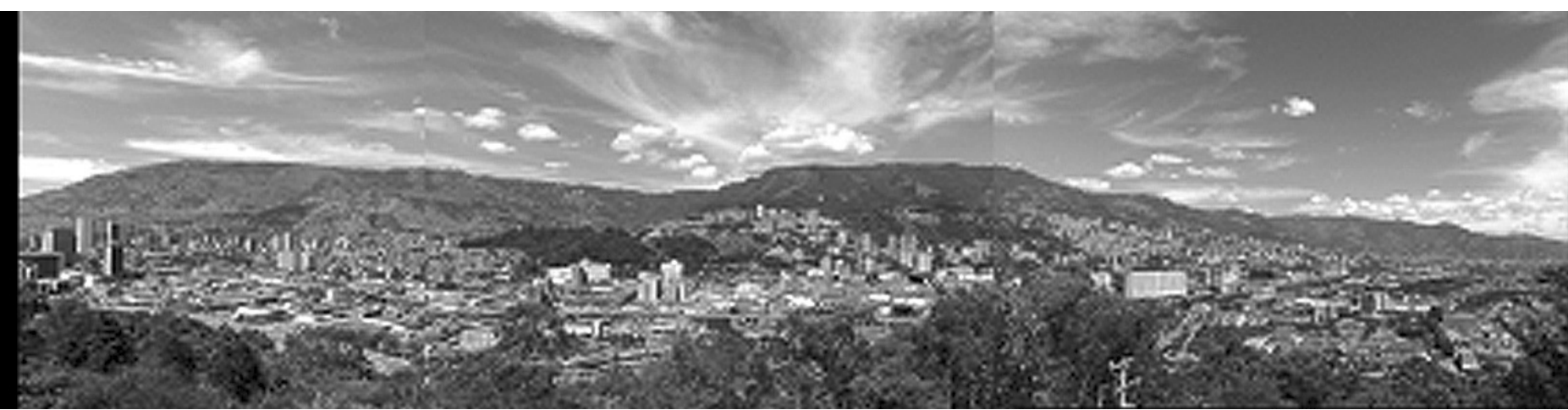




\section{MEDELLÍN METROPOLITANA. UNA APROXIMACIÓN A LA CIUDAD, LA CRISIS COMO OPORTUNIDAD}

Medellín está localizada en un valle andino muy estrecho que hace parte de la cuenca del río Aburrá Medellín, que lo recorre aguas abajo hacia el norte, sobre una altitud aproximada de 1500 metros sobre el nivel del mar, bordeado por los imponentes cerros orientales y occidentales, que alcanzan una altitud máxima de 2700 metros de altura sobre los bordes superiores de la montaña.

Se trata de un territorio en un proceso fuerte de metropolización, con la ciudad plenamente conurbada de siete de los diez municipios que componen el valle. Desde hace más de cinco décadas, sobre las laderas del norte, la urbanización informal y la pobreza endémica que existen en el país y en nuestro continente han permitido que muchísima gente viva en condiciones de inmensa precariedad. Son laderas en las que la urbanización coexiste con altos niveles de riesgo y precariedad, en zonas geomorfológicas inestables, inundables o sujetas a escorrentías, derrumbes $\mathrm{y}$ aludes frecuentes, como parte de un valle andino frágil, con montañas jóvenes e inestables, que funciona como una cuenca colectora de arroyos y quebradas urbanizadas en sus bordes, un marco natural y paisajístico de inmensa belleza.

La ciudad fue fundada en 1616 y erigida como villa de Nuestra Señora de La Candelaria de Medellín en 1675, en el marco de la denominada colonización española, dentro del departamento de Antioquia, cuya capital antigua se llamaba Santa Fe de Antioquia, hermoso patrimonio histórico, al occidente sobre

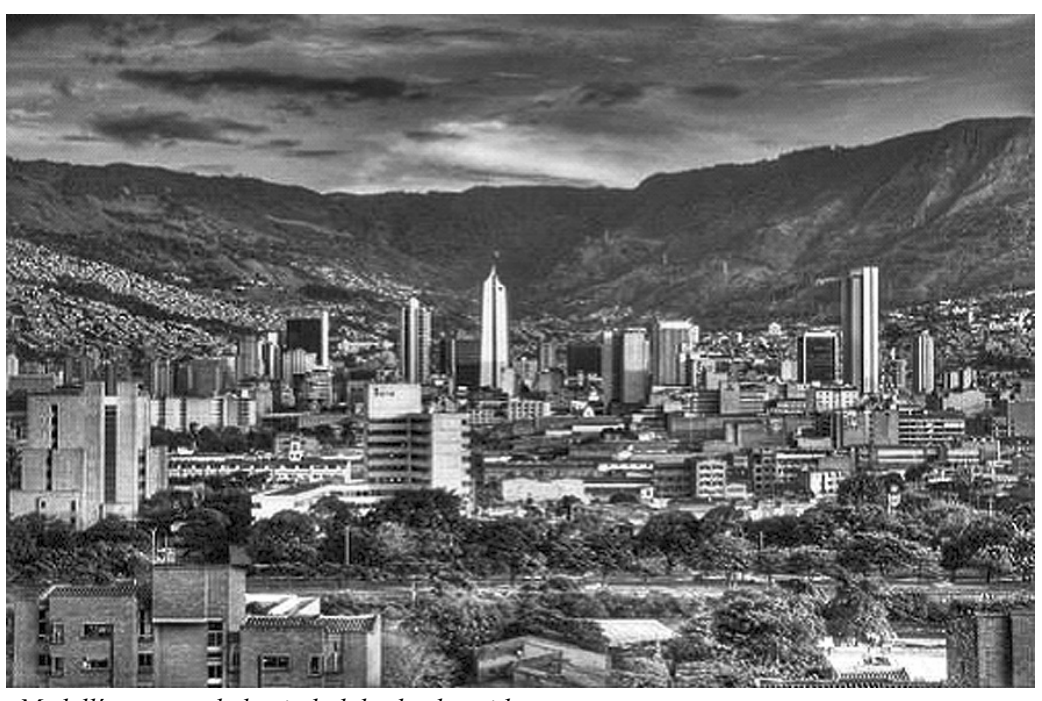

Medellin, centro de la ciudad desde el occidente.

Fuente: AMVA www.metropol.gov.co.

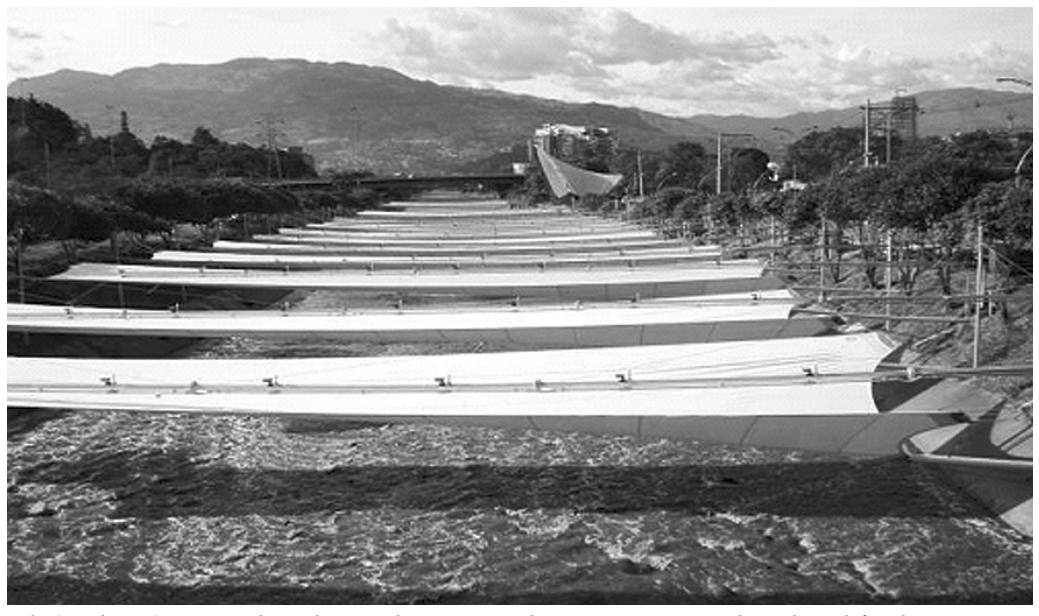

El río Aburrá aguas abajo hacia el norte, con las montañas occidentales al fondo. Fuente: foto del autor. 


\section{Jorge Pérez Jaramillo}

Centro de la ciudad cerros orientales y cruce de lineas del metro.

Fuente: AMVA www.metropol. gov.co. el valle del río Cauca, distante unos setenta kilómetros de Medellín. El centro histórico tradicional, ubicado al oriente del corazón del valle, alejado de los terrenos inundables en el pasado, tiene relativo interés, pues el "progreso" del último siglo y las transformaciones urbanas que conllevó destruyeron la inmensa mayoría de edificaciones y estructuras de valor cultural e histórico, y es un conjunto cuya masa urbana fue mayoritariamente construida durante el período de la arquitectura moderna. Sobre el sector occidental del río están los cerros tutelares de la ciudad llamados Nutibara y El Volador, en donde hay parques y restos arqueológicos, ruinas y tumbas de las comunidades indígenas precolombinas que

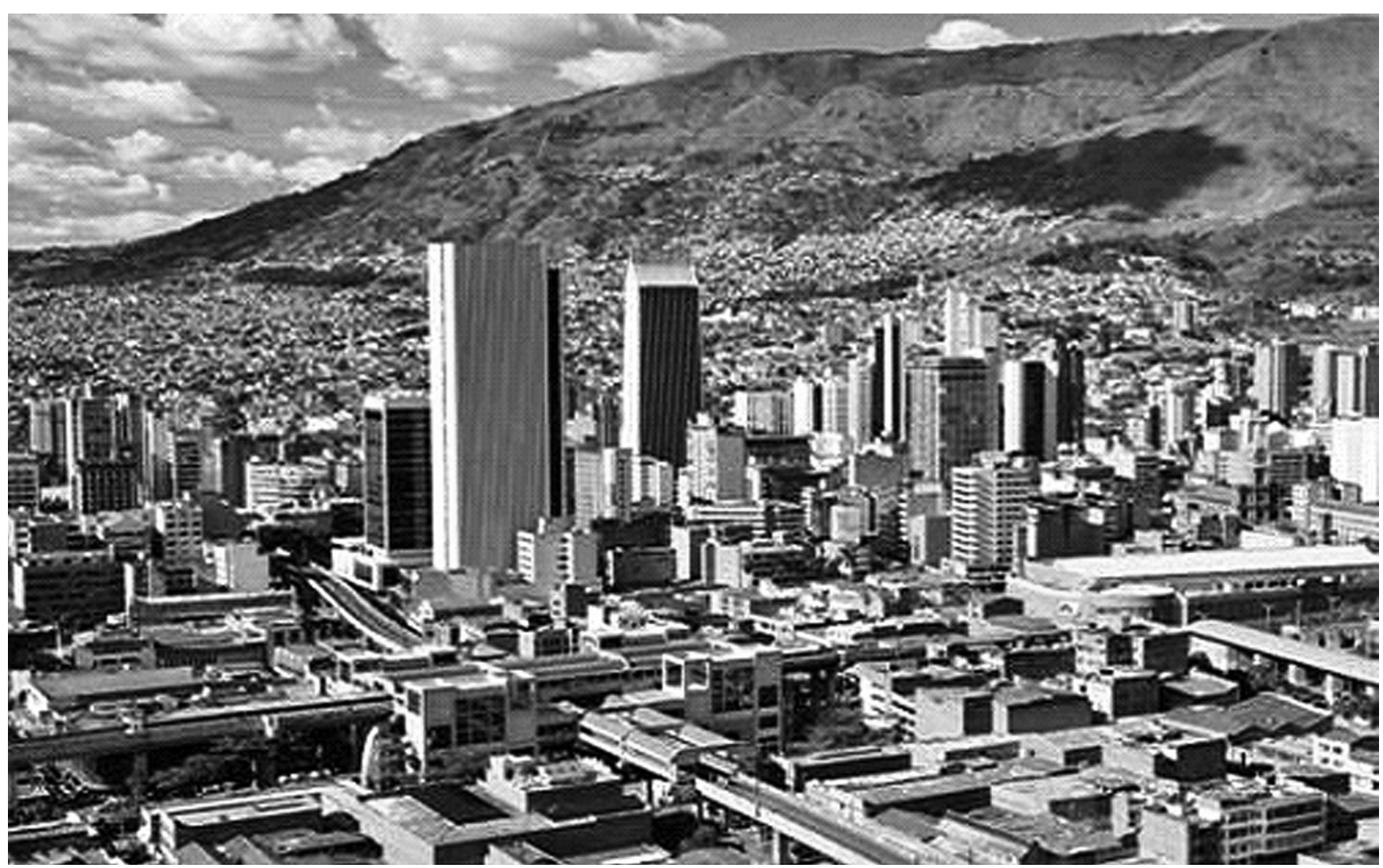




\section{MEDELLÍN METROPOLITANA.}

UNA APROXIMACIÓN A LA CIUDAD, LA CRISIS COMO OPORTUNIDAD

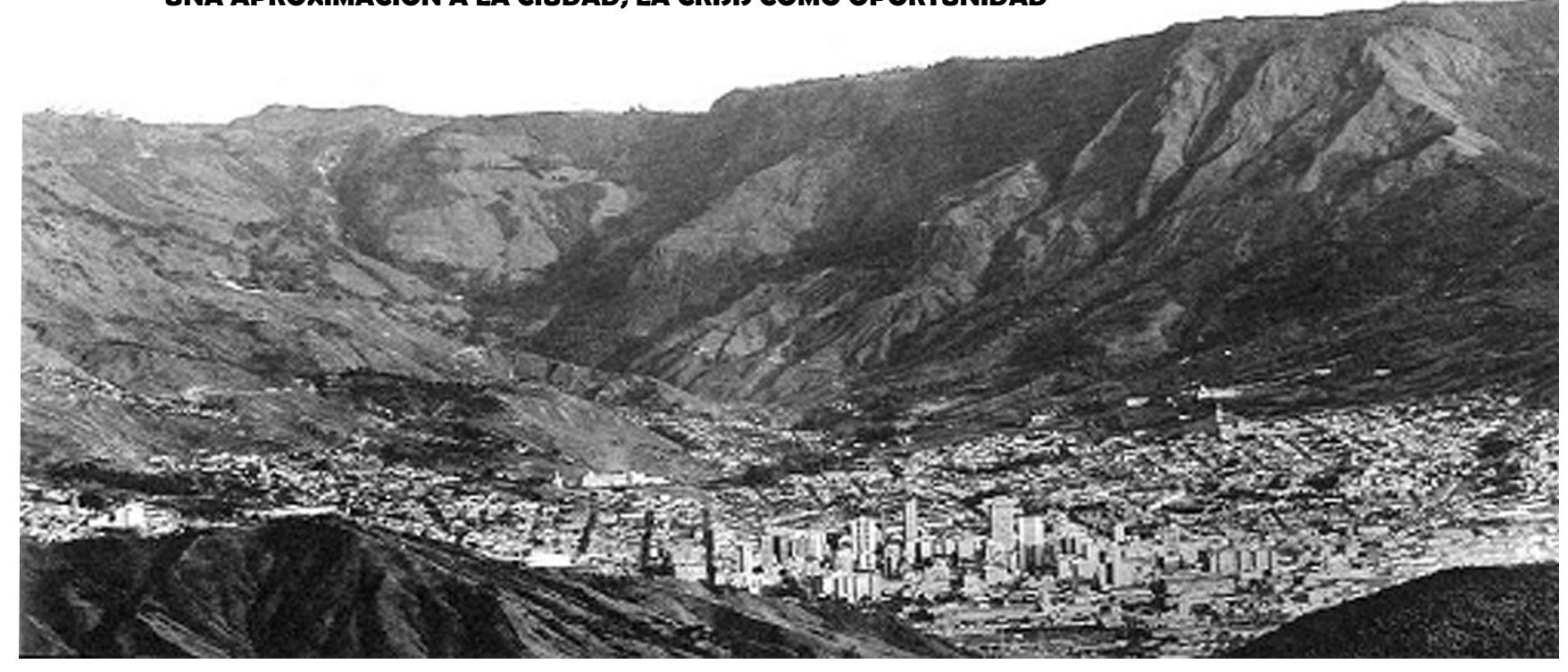

poblaron el valle desde el siglo I a. de C.

Medellín, cuando su frontera urbana llegaba solo hasta la base

Son clave en la estructura urbana general de hoy el río como elemento natural fundamental, el metro como sistema estructural de movilidad, con dos ramales (uno que va de sur a los cerros orientales. Fuente: Archivo Gabriel Carvanorte al costado del río y entra al centro de la ciudad y el ramal occidental llamado línea jal, fotógrafo, 1970. B), sumados a los metro-cables, el sistema Metroplús (BRT) y el tranvía en construcción. El metro comenzó a finales de la década de los 80 como un sistema normal de trenes y ha evolucionado hasta un sistema multimodal que incluye innovaciones como el metrocable, que en realidad es un invento local, ya que nunca antes se había utilizado como medio para el transporte masivo.

Una de las condiciones más importantes de la conformación de la ciudad es que las diversas microcuencas hídricas que configuran el Valle del Aburrá en muchos casos son manejadas como sistemas lineales de espacio verde y espacio público, elementos que tienen su definición general desde la formulación del plan Piloto Regulador en 1950 (P. WIENER y J. LL. SERT), que estructuró una base de la ciudad planificada, que en medio de la masiva expansión mediante procesos invasivos no articulados con las políticas públicas durante las décadas recientes aún hoy es evidente, y aprovecha el río y su cuenca como base natural fundamental de la ciudad. 


\section{Jorge Pérez Jaramillo}

Sobre el norte de la ciudad aparecen las denominadas comunas, sectores resultado de la expansión mencionada, caracterizados por un alto grado de pobreza material, exclusión social y precariedad e informalidad urbana, parcelas de la "no ciudadanía", aquella parte de la población que no está plenamente integrada a la vida ciudadana, y que para algunos sectores sociales al estar localizada a lo lejos, estorba poco y aparentemente causa menos problemas que cuando está en el medio de todos. La masa crítica de la pobreza está en esta zona norte, tanto en el oriente como en el occidente, resultado de una especie de planificación territorial de la exclusión, que coincidió con la expansión urbana del país y que construyó mediante procesos muy complejos de urbanización de carácter informal e invasivos de los terrenos grandes extensiones de ciudad.

Hoy la frontera está en la mitad de sus laderas, un proceso invasivo muy destructivo del entorno que ha generado toda suerte de conflictos, exclusión y degradación urbana y social. Con las frecuentes temporadas de lluvias, las comunidades coexisten con los más altos niveles de riesgo, lo cual se evidenció en forma trágica en diciembre del año 2010, cuando un alud sepultó a más de 70 personas en el barrio La Gabriela del municipio de Bello.

A lo largo del centro del valle va el río, que en realidad ha operado como un canal de drenaje importante y profundamente contaminado durante décadas, como cloaca urbana a cielo abierto. Sobre su estructura se ha venido trabajando para recuperarlo como sistema natural y elemento estructurante de la ciudad del futuro. Llevamos más de quince años desarrollando un programa de rehabilitación con un plan de tratamiento y renovación, en el cual está previsto que el río en diez años recupere aproximadamente un $93 \%$ de su calidad hídrica y sea realmente un elemento integrador de la ciudad metropolitana.

Los bordes de las montañas del valle, que tienen unos 100 kilómetros de longitud, alcanzan una altura aproximada de unos 2700 metros sobre el nivel del mar y son ricos en reservas naturales de gran importancia, que incluyen no solo ecosistemas forestales estratégicos, sino cientos de quebradas, cuerpos de agua y fuentes de agua que descienden desde lo alto para configurar la base territorial de la ciudad.

El valle contiene diez municipios, y su población actual es de 3.500 .000 de habitantes aproximadamente. En la ciudad contemporánea, específicamente la región del Valle de Aburrá con su evolución metropolitana, el territorio urbano ya no es necesariamente el municipio. En el siglo XXI la ciudad son las regiones metropolitanas. Tampoco es solo el

Cuaderno Urbano. Espacio, Cultura, Sociedad - Vol. 12 - No 12 (Junio 20I2)- Pp. 138-169-ISNNI666-6186
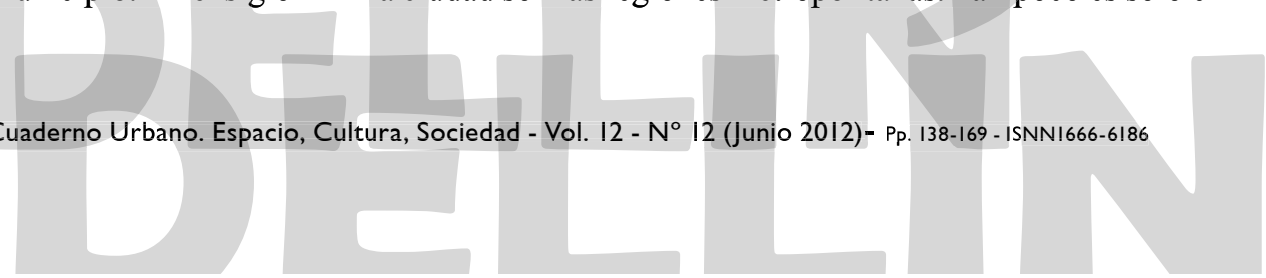


\section{MEDELLÍN METROPOLITANA.}

UNA APROXIMACIÓN A LA CIUDAD, LA CRISIS COMO OPORTUNIDAD

entorno urbanizado; es también el regional sobre el cual gravitan el sistema natural y funcional, los recursos que demanda y los territorios que los proveen, un sistema complejo de escala supramunicipal que sustenta la ciudad.

\section{MEDELLÍN, UNA APROXIMACIÓN HISTÓRICA Y SOCIAL}

Colombia es una república central unitaria, con una Constitución política y un órgano legislativo único para todo el territorio. En 1991, tras décadas complejas de gran convulsión política y social en todo el territorio, desarrollamos una reforma constitucional inspirada en el llamado Nuevo Derecho, que abrió un espectro político y social más moderno, ampliamente participativo y pluralista, con énfasis en un sistema de descentralización política y administrativa muy fuerte. Fue una apuesta por un país plural y moderno, mucho más democrático e incluyente. Desde entonces, en algunos aspectos, el país se ha convertido en un relativo laboratorio urbano, gracias al inmenso protagonismo y fortaleza que se le ha dado a la célula municipal como elemento de gobierno y gestión de la democracia y a la creciente expansión urbana.

Nuestro régimen político-administrativo ofrece a los municipios amplia autonomía, autoridad presupuestaria y operativa, alcanzando incluso niveles excesivos de autonomía en algunos temas, lo cual le ha dado al país por más de dos décadas la oportunidad para avanzar mucho, tanto en lo político como en lo normativo. Dicen algunos expertos que la legislación urbana de Colombia en la actualidad es tan buena que a pesar de lo que hemos avanzado, los colombianos todavía no la hemos aprovechado en su plenitud.

La interesantísima localización geoestratégica de Colombia, que como cruce de caminos en el corazón continental tiene una riqueza en biodiversidad que - según dicen algunos ambientalistas - es una de las más importantes del planeta, sumada a la ventaja de tener dos mares - pues tenemos costa sobre el mar Caribe y el Pacífico-, llanuras, montañas andinas y selvas amazónicas, al hecho de ser un territorio productor de agua y gran riqueza mineral y natural, la convierten, en suma, en una suerte de paraíso ambiental, y también en un botín global.

El $95 \%$ de la población está asentada desde esta franja oriental de la cordillera de los Andes hacia el Caribe y el Pacífico, y más de la mitad del territorio está completamente despoblado. Es precisamente en esta zona donde Medellín y las grandes ciudades, como Bogotá, Cali y Barranquilla, están localizadas. 


\section{Jorge Pérez Jaramillo}

Si bien el potencial de nuestras zonas selváticas es inmenso, también es cierto que son áreas aptas para la ilegalidad, y es precisamente ahí donde se concentra buena parte de nuestros conflictos y violencia.

Medellín, localizada al noroccidente del país, está en medio de los Andes, y por tanto muy distante de los mares y los puertos que la comunican con los mercados globales. Ya desde el siglo XIX la ciudad fue centro de una región que nacía, industriosa, emprendedora, y era una de las poblaciones económicamente más importantes, una región que a escala colombiana tuvo y mantiene un papel singular. Durante décadas, desde el final del siglo XIX, fue elemento fundamental de la minería de oro y plata, así como del sector cafetero. Como mayor productora de café de Colombia, a su vez uno de los países más importantes en la producción mundial, Medellín ha sido un centro económico fundamental. La comunicación pasaba por un ferrocarril, que se construyó uniendo la población con el río Magdalena, el eje del desarrollo más importante del país, que recorre todo el territorio a lo largo de la cordillera de los Andes y desemboca en el mar Caribe.

A partir del denominado Ferrocarril de Antioquia, Medellín y la región tuvieron una conexión muy grande con Europa y los EE. UU. y un gran auge comercial y cultural desde esos tempranos años. Esto significó información, educación, negocios, flujo de población, creación de bancos, emprendimientos universitarios, fundación de periódicos, generación de movimientos culturales, literarios, la creación de una ciudad muy moderna y avanzada en términos ideológicos en medio de su contexto provinciano. Un ejemplo excepcional de esto es que a principios del siglo una de las primeras y más importantes líderes feministas del mundo, María Cano, surgió en Medellín.

Este proceso que podemos llamar de "esplendor" de la naciente ciudad duró relativamente hasta la década del 70, momento a partir del cual la ciudad entró en una crisis muy profunda, con gran complejidad, muchos matices y expresiones.

Todo esto coincidió con la etapa en que se consolidó la urbanización del país. Durante las décadas del 50, 60 y 70, Colombia tuvo inmensos procesos migratorios internos del campo a las ciudades, y pasó de tener un $75 \%$ de su población en el campo a conservar hoy solo un $25 \%$, y el $75 \%$ de su gente viviendo en ciudades. Hoy contamos con un 85 $\%$ de población que habita en las ciudades. Esta condición, que no es extraña en América Latina, para nosotros es un proceso muy reciente y conflictivo, un momento crucial de la sociedad. 


\section{MEDELLÍN METROPOLITANA.}

UNA APROXIMACIÓN A LA CIUDAD, LA CRISIS COMO OPORTUNIDAD

A nivel regional, Medellín concentra más o menos el $65 \%$ del Producto Bruto Interno de todo el departamento de Antioquia, y esto incluye la generación de riqueza, pero también de pobreza, de problemas y de alternativas para el desarrollo regional. Esa pequeña ciudad, en términos geográficos, es sin embargo grande en población y problemas, e influye con su huella ecológica y su dinámica urbana prácticamente sobre el $80 \%$ del territorio del departamento de Antioquia, área sobre la cual la ciudad urbanizada impacta de manera directa, demandando y consumiendo bienes y recursos ambientales. Es decir que para que la ciudad opere y sea sostenible, requiere territorios que le provean recursos naturales, como agua, oxígeno y otros como alimentos y energía, entre muchos más, una realidad común con muchas regiones metropolitanas en la actualidad.

En la década del 70 colapsó nuestra industria manufacturera. Problemas de competitividad ante las economías emergentes asiáticas, sumados a nuestras condiciones de localización geográfica lejana a los puertos, el atraso aún vigente en infraestructura y la gravísima destrucción de la antigua red férrea configuraron condiciones muy críticas para nuestra economía. Asistimos al proceso de quiebra de nuestras grandes fábricas y el consecuente desempleo masivo. Adicionalmente al problema industrial, el pacto mundial del café, del cual dependíamos en buena medida, hizo que el precio en los mercados internacionales se redujera a cifras críticas en relación con su precio promedio tradicional, con el consecuente deterioro de la economía regional, que derivó en deterioro de la economía agraria y el empleo rural, cuestiones que van a impactar fuertemente en la ciudad.

En este período, como agravante adicional, aparece con inusitada fuerza la corrupción pública colombiana, que si bien existía en la región a escalas menores, no había alcanzando la magnitud de ese momento. A finales de los años 70 y 80 la clase política local, que siempre tuvo un nivel relativamente alto de liderazgo y control del poder y cierta credibilidad y representatividad, también hizo crisis como esquema clientelista y burocrático, poco transparente, como una democracia de pequeños clanes que perdieron el rumbo y la confianza popular. Sin embargo, esto no era todo: como epílogo aun peor a la "película de la crisis" llegó el capítulo del narcotráfico.

Una sociedad de comerciantes muy hábiles, con inmensa tradición cultural y conexiones históricas con el contrabando hizo que produjéramos para este tiempo los mejores traficantes de narcóticos del mundo. Esta crisis, con su ausencia de empleo y las precariedades institucionales y sociales acumuladas, sirvió como caldo de cultivo para darle oportunidades a mucha gente en los "nuevos negocios" y hacer que el sistema del narcotráfico funcionara eficazmente. 


\section{Jorge Pérez Jaramillo}

A nosotros no nos ocurrió una guerra civil ni nos ocupó violentamente un Estado distinto, nosotros mismos, los habitantes de Medellín, nos estuvimos matando durante años. Pablo Escobar, el mayor delincuente que conocimos, puso bombas por todo el país y voló edificios públicos y aviones sin ninguna vacilación, enfrentando al "establishment" y sus grupos de poder, asesinando con bandas de sicarios organizados a cientos de colombianos de bien. En esa ciudad, en medio de esa guerra, vivimos nosotros.

Medellín fue durante años una marca internacional por sus problemas y errores, por la muerte, por la corrupción y la violencia. Cuando ocurren ese tipo de fenómenos en una ciudad, esta termina identificada con ello exclusivamente y se pierden de vista su complejidad y contenidos, porque en el mundo actual hay mucha ignorancia y relativa simplificación de la complejidad real. Por ende, por muchos años, prácticamente se hablado y "distinguido" a Medellín en el mundo únicamente por el narcotráfico. Pero la historia de Medellín, desde siempre, se ha caracterizado por mucho más que eso.

Ha sido y sigue siendo muy difícil desde nuestra situación local resolver un problema global como el narcotráfico. Hoy es notable Ciudad Juárez, ayer fue Medellín y mañana va a ser otra ciudad. El problema es que nosotros ponemos muerte, dolor y miseria y sufrimos el abandono y la estigmatización internacional. Como sociedad, lo peor que nos ha ocurrido ha sido el impacto del narcotráfico en nuestra comunidad, en la economía y en la política.

Por décadas, estos fuertes niveles de precariedad democrática y corrupción política y empresarial, que sumados al contrabando y el narcotráfico se desarrollaron en Medellín, permearon diversos espacios sociales y políticos y derivaron en una sociedad colapsada ante su propia encrucijada, con expresiones dramáticas de violencia, terrorismo y muerte.

Una comunidad urbana con gran concentración de riqueza, tierra y poder entre pocas personas, en la que por varias décadas cerca del $60 \%$ de la población ha vivido en condiciones de pobreza y desempleo (cuando no empleo precario), exclusión social y territorial, ha sido fuente de conflictos diversos, que derivaron en la conformación de grupos organizados alrededor del tráfico de narcóticos, la extorsión y la delincuencia común, pandillas con gran poder económico y agresión social, estructuras que en muchos escenarios desplazaron y suplantaron las organizaciones formales de la sociedad.

En un esquema global, en el cual desde hace varias décadas países como los nuestros reciben abiertamente precursores químicos y armas ligeras desde otros territorios, en me- 


\section{MEDELLÍN METROPOLITANA. UNA APROXIMACIÓN A LA CIUDAD, LA CRISIS COMO OPORTUNIDAD}

dio de un mercado global sofisticado y corrupto, con estructuras poderosas de lavado de activos y recursos financieros y un mercado de consumo cada vez mayor, nuestra región - debido en parte a su localización geoestratégica, su entorno rural de selvas y mares y su tradición mercantil- se constituyó en uno de los lugares de "excelencia" para el tráfico ilegal. La expansión del narcotráfico a partir de los años 80 generó estructuras tan poderosas como los llamados "cárteles", que enfrentaron al Estado con niveles de violencia hasta entonces desconocidos, que como complemento a los problemas antes descritos, hicieron de Medellín y su entorno un "infierno" prácticamente inviable como estructura social, con indicadores de muerte violenta cercanos a los 6300 homicidios en el año 1991 (381 homicidios por cada 100.000 habitantes), situación sin antecedentes en el mundo civilizado para una región que no fue foco de una guerra religiosa, territorial o política "formal".

Medellín junto a sus universidades, con escuelas artes y oficios y de ingeniería desde finales del siglo XIX y facultades de arquitectura desde la década del 40, cuando se fundó la Facultad de Arquitectura de la UPB (en 1942), ha tenido una relativa tradición de planificación. Ya a comienzos del siglo XX se creó una Sociedad de Mejoras Públicas, organismo cívico que se ocupó de planear la naciente ciudad. En 1949 Le Corbusier visita la ciudad y promueve la creación de un plan, y se formula el Plan Piloto Regulador, para lo cual - como se mencionó antes - se contrató a José Luis Sert y a PAUL Wiener, lo que significó un importante paso para nuestro futuro como ciudad. Podemos decir que todo lo que hacemos ahora se basa en una tradición de una sociedad que ha pensado y ha intentado prever su futuro a través de un modelo de ciudad.

Inspirado en las teorías más avanzadas vigentes por esos años, una de las cosas más interesantes que nos ofreció el Plan Piloto Regulador de Medellín fue la zonificación del área industrial de la ciudad hacia el sur y su reconocimiento de la base natural, como son las quebradas, los ríos y otros accidentes geográficos, como elementos fundamentales para armar la ciudad.

\section{LA CRISIS COMO OPCIÓN}

Lo más importante de nuestra crisis es que fue lo suficientemente grande como para que hubiera que resolverla. Uno de los problemas más serios con que se están enfrentando las ciudades actuales es que en casi todas hay quien sabe cuáles son los problemas, pero en casi ninguna hay consenso sobre el proyecto de ciudad que requieren. Muchas de ellas cuentan con diagnósticos, indicadores, planes, y siempre los bancos internacionales,

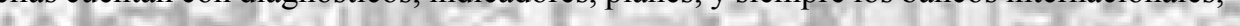




\section{Jorge Pérez Jaramillo}

como el BID o el Banco Mundial, apoyan estudios, mediciones e indicadores. Es casi imposible que una ciudad hoy en día no tenga eso, pero es muy común que ninguna ciudad tenga un proyecto de futuro.

Un proyecto de futuro es una visión de largo plazo, estratégica, participativa y consensuada y con liderazgo compartido de diversos sectores de la sociedad. Un proyecto de futuro no es un plan que define el Estado, sino un esfuerzo político y técnico de toda la sociedad, pensando de manera colectiva qué va a hacer con su ciudad.

Si bien Medellín nunca tuvo un proyecto pleno de esta naturaleza, por lo menos la fuerza de su crisis forzó un inmenso diálogo colectivo que generó no solo procesos sociales formales, sino una riqueza de organizaciones comunitarias que han hecho que la ciudad, en medio de sus dificultades, haya mantenido vitalidad y claridad y haya consolidado una suerte de pacto social, un consenso sobre las prioridades y los retos de futuro.

En esa crisis se produjo algo que no tenía muchos antecedentes. Una sociedad característicamente muy clasista y excluyente, conservadora, segregada y segmentada, seguramente como consecuencia de los muy graves problemas que estábamos enfrentando, decide que hay que trabajar juntos, recogiendo todas las banderas de lo que hicimos bien y mal en el pasado, entendiendo que si no lo hacíamos no había salida. Cuando se vive en una sociedad que "muere de crisis", es casi lógico que todo el mundo se tome en serio el problema, supere barreras e inconsciencia y decida trabajar por una solución. Este fue uno de nuestros hechos clave para avanzar.

Después de casi una década de trabajo en el proceso de crisis, con la denominada Consejería Presidencial para Medellín, entre los años 1995 y 1998 formulamos el Plan Estratégico Medellín y el Valle de Aburrá 2015, proyecto ampliamente participativo, liderado por ciudadanos, la Alcaldía y el Programa de las Naciones Unidas para el Desarrollo, que logra trabajar con más de 1500 líderes representantes de la ciudadanía y formular este ambicioso proyecto, representativo de un momento de inflexión en que la sociedad hace balance de todo lo que se hizo durante el siglo, para comenzar una nueva etapa. El plan definió cinco líneas estratégicas, que incluyen los proyectos priorizados, y desde entonces, nuestra sociedad ha venido trabajando con estos lineamientos:

Linea 1: Ciudad educadora que además sustenta su desarrollo sobre la base de la cualificación del talento humano. 


\section{MEDELLÍN METROPOLITANA. \\ UNA APROXIMACIÓN A LA CIUDAD, LA CRISIS COMO OPORTUNIDAD}

Línea 2: Epicentro de politicas sociales y culturales en América Latina.

Linea 3: Ciudad metropolitana descentralizada, participativa y centro internacional de la convivencia.

Línea 4: Centro logístico de servicios avanzados en la región andina como base de una nueva dinámica industrial.

Linea 5: Ciudad metropolitana accesible, acogedora, integrada y con calidad ambiental.

¿Qué significa, entonces, la crisis como opción? Que todos quienes integramos la sociedad organizada nos implicamos en el análisis y la construcción del plan, de tal manera que el proyecto urbano de la ciudad de Medellín se convirtió en el tema incluyente. Surgió así una organización ciudadana con un fuerte criterio político, cívico y de participación activa en los proyectos urbanos. Esto quiere decir que la política en Medellín dejó de ser solo un asunto de quienes ejercen en la política partidaria; los ciudadanos nos tomamos en serio los problemas de la ciudad y nos dimos cuenta de que ser actores políticos no era solo una oportunidad, sino una obligación para poder superar la crisis. Frente a eso surge una ciudad renovada por una ciudadanía activa, con esperanza de futuro y con muchas nuevas formas intervención y actuación integradas en el territorio. Los ciudadanos nos incluimos en el proyecto de cambio y formamos parte de la solución. Fue un proceso de cambio social y cultural muy importante.

De la tradicional prevalencia de intereses particulares (el "combo" y la "pandilla") aprendimos a actuar como un grupo de ciudadanos organizados. Las ciudades normalmente operan con base e intereses sectoriales de pequeños grupos de poder que toman decisiones por encima de los intereses generales. La mayoría deja que eso suceda. Por eso en Medellín comprendimos también la necesidad de hacer acción política. Entendimos que había que participar de otra manera. De hecho, conviene recordar que el rol de las universidades fue fundamental, las grandes acciones desde la planificación y la gestión urbana, el urbanismo y la arquitectura estuvieron vinculadas con la experimentación y estudio desde las universidades. En resumen, se podría decir que en nuestra ciudad hubo un proceso de crisis, con reacción e implicación de los ciudadanos, y después un proceso de diálogo colectivo que trajo como resultado un proyecto político y el cambio.

\section{LOS RETOS DE LA INTEGRACIÓN METROPOLITANA}

Medellín, en relación con su presupuesto de ingresos, es una ciudad rica que por la estructura del Estado colombiano cuenta con mucha autonomía y capacidad de inversión. Los alcaldes de nuestras ciudades tienen amplio poder sobre el presupuesto y facultades 


\section{Jorge Pérez Jaramillo}

El valle de Aburrá y la región central de Antioquia.

Fuente AMVA www. metropol.gov.co. para ejecutarlo. El presupuesto de la ciudad es cercano a los 1800 millones de dólares anuales (Gaceta Oficial N. 3959 Presupuesto 2012, que equivalen a una cifra per cápita anual de \$727 dólares de USA), y obedece mayoritariamente al pago de impuestos, recursos transferidos desde la Nación y las empresas públicas de Medellín de propiedad municipal. Un presupuesto de esta magnitud, bien manejado, ayuda mucho para hacer una gestión urbana importante. Sin embargo, la ciudad es mucho más que un municipio,

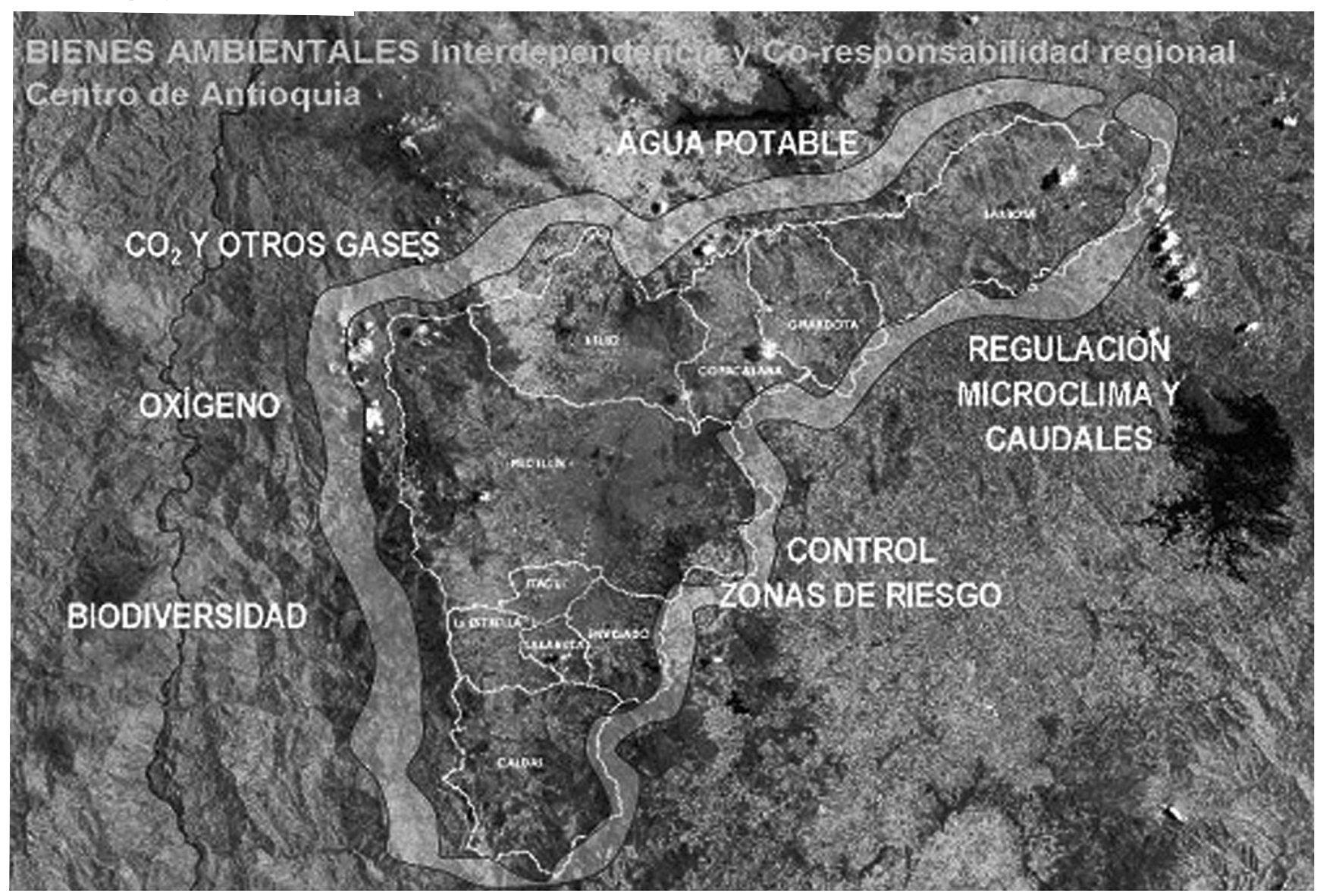




\section{MEDELLÍN METROPOLITANA. \\ UNA APROXIMACIÓN A LA CIUDAD, LA CRISIS COMO OPORTUNIDAD}

es una realidad metropolitana de diez municipios, con altos niveles de pobreza y atraso, fuerte dependencia sobre la dinámica económica de Medellín y mucha fragmentación territorial.

Hoy, en el mundo, nos enfrentamos más que a municipios a regiones metropolitanas en expansión. Ya casi ningún municipio importante opera solo o en modo exclusivo, todos tienen una gran interdependencia. Algunos son ciudades-dormitorio, otros proveen servicios ambientales, son centros académicos o industriales, pero coinciden en poseer grandes interdependencias entre ellos. Nosotros en el Valle de Aburrá tenemos que abordar los problemas de una región metropolitana muy claramente definida. En este caso, los límites no se definen por la planificación, sino por la propia forma del valle, pues la configuración del territorio hace que esté muy claramente integrado todo el sistema de municipios y la región. Naturalmente las fronteras urbanas se fueron diluyendo, a medida que los perímetros municipales se expandieron. Durante varias décadas se configuró "una ciudad que se extiende por el territorio de diez municipios", tal como lo planteó Sergio Bustamante, director del Área Metropolitana en 2004.

La pregunta necesaria en estas condiciones sería: ¿es sostenible la ciudad? Resulta que el $99.9 \%$ de los recursos ambientales que consume Medellín metropolitana no los produce ella misma, provienen de su entorno regional. De la misma manera, hoy casi ninguna ciudad es autoabastecida en cuanto a los recursos que consume de oxígeno, agua potable, alimentos, energía, etcétera, y además produce impactos regionales ciertos sobre territorios vecinos, por generación de residuos, aguas servidas, contaminación del aire y dinámicas territoriales y urbanas, entre muchas otras cosas.

\section{URBANIZACIÓN Y SOSTENIBILIDAD. CIUDAD COMPACTA VERSUS CIUDAD DIFUSA}

En el contexto de la tendencia común entre los ciudadanos de considerar propuestas amigables con el ambiente, el modelo de casa unifamiliar en el campo es pertinente, según las condiciones de Medellín, analizar la opción del concepto de ciudad densa y compacta. Sobre un predio que estaría ocupando una familia típica para su vivienda unifamiliar en la ciudad difusa y de baja densidad, en un esquema de ciudad compacta tendríamos una densidad mucho mayor, sobre una parcela similar. Esto significa que el consumo total de planeta por vivienda difiere sustancialmente en ambos modos de urbanización. 


\section{Jorge Pérez Jaramillo}

Medellín vista desde la ladera nororiental.

Fuente AMVA www.metropol. gov.co.
En el modelo de baja densidad, cada persona tiene que movilizarse al centro de servicios de la ciudad con alta frecuencia, distancia diaria por persona, alto consumo energético, generación de emisiones y riesgos de accidentalidad e importante gasto de tiempo en transporte, es decir, el modelo suburbano tan ampliamente utilizado en nuestros países es muy poco sostenible ambientalmente.

Generalmente, el imaginario aceptado plantea que quien vive en una casa, rodeado de árboles y jardín, es ambientalmente amigable con el planeta, lo cual sin duda es relativo. Lo que es más grave aun es que este modelo suburbano impermeabiliza el territorio e incrementa las escorrentías y las crecientes de los ríos, porque transforma bosques y áreas naturales que capturan agua, y otra cosa bien diferente es un jardín, que es un espacio transformado diferente de un área natural, integrada con el sistema ecológico.

Además de las dificultades anteriores, en el caso de la ciudad difusa, el costo de mantenimiento de la red de infraestructura urbana versus los ingresos recibidos con el presupuesto público, comparado con una ciudad compacta, es mucho más alto. Indudablemente, es mucho más racional y eficiente proveer a los ciudadanos espacios públicos, bibliotecas, transporte, salud, educación con el presupuesto de una ciudad compacta que en una difusa

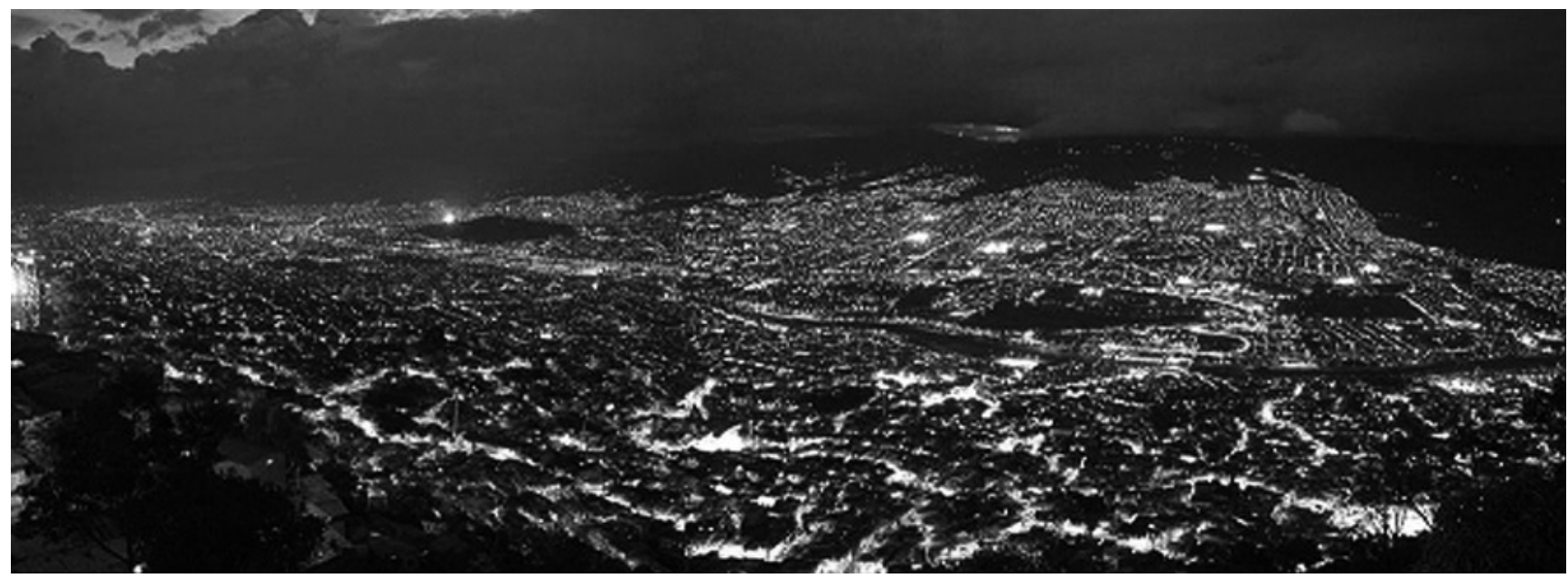




\section{MEDELLÍN METROPOLITANA. UNA APROXIMACIÓN A LA CIUDAD, LA CRISIS COMO OPORTUNIDAD}

y expandida. Finalmente, en ambos casos, es necesario tener una visión a largo plazo y considerar que con el incremento de población, el problema de ocupación territorial será cada vez mayor y los retos de sostenibilidad más complejos.

El territorio es un recurso no renovable. Una vez que se consumen sus atributos y se urbaniza, se va y no vuelve. Como consecuencia de la suburbanización y la redensificación sin planeación, hoy no hay vías adecuadas, no hay espacios públicos y no hay suficiente dinero para hacerlo. Nadie quiere pagar el precio.

¿Qué le ha pasado como ejemplo a Medellín? Hemos expandido críticamente la frontera urbana sobre las laderas, una expansión al límite. Un valle rico en quebradas y ríos, en me-

Centro de Medellín visto desde el cerro Nitibara hacia el norte.

dio de entornos mayoritariamente impermeabilizados, con la montaña en proceso de sub-urbanización y poco suelo urbanizable disponible, padece entre otros problemas que el agua de las quebradas está llegando muy rápidamente al río con gran capacidad de arrastre en los cauces, generando deslizamientos, inundaciones y alto riego, con una frecuencia cada vez mayor. Es decir, además del consumo de suelo, la expansión de la urbanización tiene mucho que ver con las contradicciones con la estructura ecológica principal del territorio y la sostenibilidad de la ciudad.

Enmarcados en la crisis histórica que venimos enfrentando, en el año 2004 comienza este esfuerzo renovador de nuestro gobierno local liderado por Sergio Fajardo, como una consecuencia natural

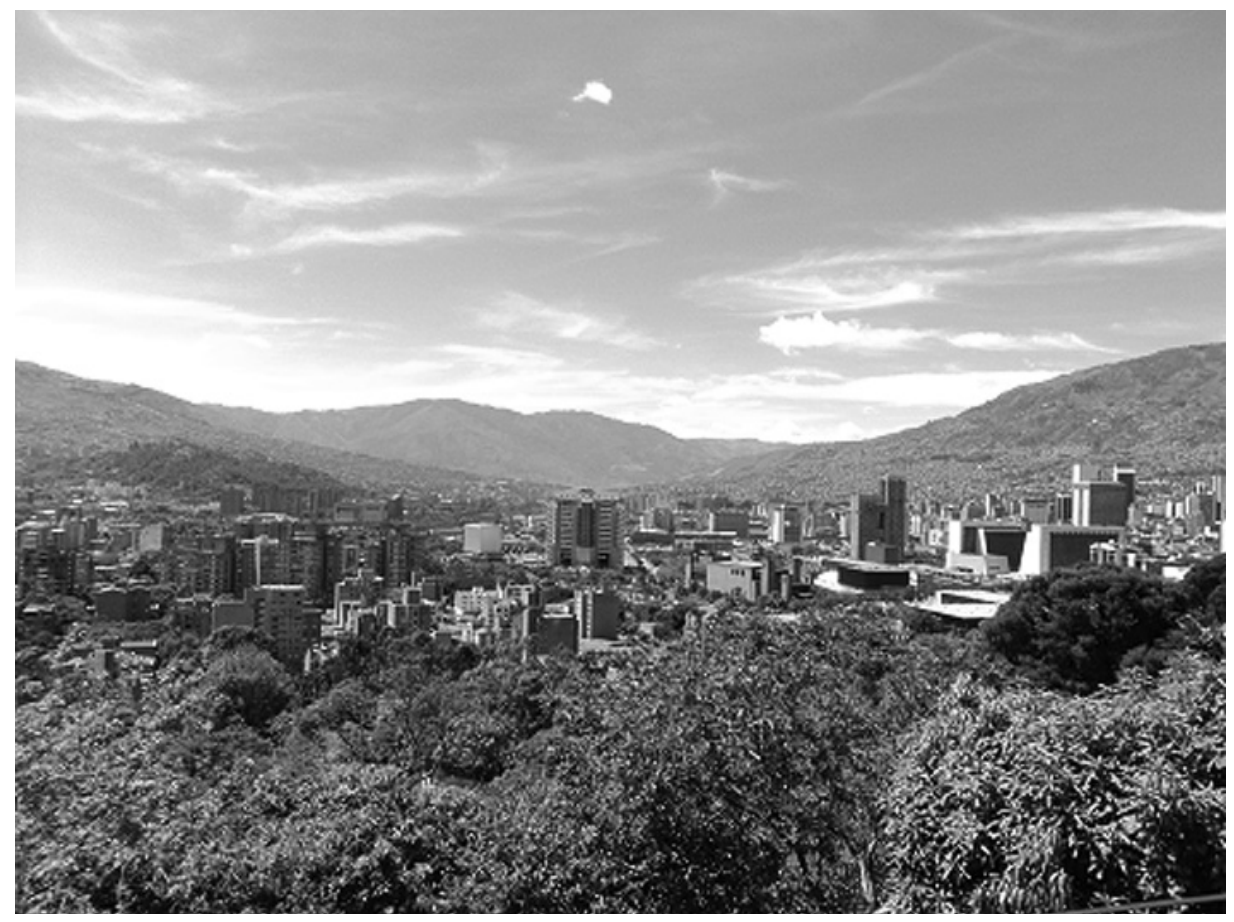




\section{Jorge Pérez Jaramillo}

de un movimiento cívico conducido mayoritariamente por una generación que para ese entonces tenía un promedio de 40 años y venía discutiendo y construyendo — desde los años 80- diversos temas de la ciudad. Se trata de una generación harta de la impotencia de la clase política para cambiar la realidad, que un buen día, tras muchos esfuerzos relativamente fallidos, dijo "no va más, hay que tomar el poder político para cambiar". Se creó un movimiento cívico y político de gente representativa de muchos matices económicos, generacionales, sociales, una especie de amalgama social muy compleja que se llamó el Movimiento Ciudadano. Este movimiento, tras un primer intento electoral en el año 2000 , fortalece su postura, gana liderazgo y convocatoria, y gracias a su propuesta y a los excesos y escándalos de la política vigente, poco consecuente con los procesos sociales y políticos antes descritos, triunfa en las elecciones de 2003 para la alcaldía de Medellín.

Durante el período 2004-2008, gobierna el alcalde Fajardo, quien interpreta de manera excepcional el proceso colectivo y ciudadano emprendido años atrás y gestiona un gobierno innovador, altamente ejecutivo, que fortaleció la acción pública y ejecutó un inmenso conjunto de proyectos y obras focalizadas en la educación y la justicia social, momento histórico de cambio en nuestra política local.

A escala metropolitana, a partir de un proyecto planteado por Sergio Bustamante como director del Área Metropolitana del Valle de Aburrá, consecuencia del triunfo del Movimiento Ciudadano, tuvimos ocasión de gestionar un amplio proceso de planificación regional, que explico a continuación.

Liderado por la Junta Metropolitana, integrado por los nueve alcaldes de los municipios del valle, el gobernador y dos concejales, un conjunto de autoridades políticas representantes de los partidos tradicionales - a excepción de Sergio Fajardo - se constituyó en un espacio para la más plural y democrática concertación política, en el que aprendimos las complejidades de la política y que se requieren amplios niveles de consenso y participación para el desarrollo.

En nuestro país contamos con la Ley 128 - Ley Orgánica de las Áreas Metropolitanas, de febrero de $1994(*)$ - que nos permite desarrollar competencias de planificación supramunicipal y trabajar de manera asociativa ejerciendo autoridad ambiental urbana y de transporte. Nuestra región creó este instrumento en 1982, el Área Metropolitana del Valle de Aburrá www.metropol.gov.co, entidad en la cual, durante el período 2004-2008, formulamos un proyecto de planificación compartida y concertada entre los diez municipios del valle, un proceso de planificación y gestión innovador e integrado. 


\section{MEDELLÍN METROPOLITANA. UNA APROXIMACIÓN A LA CIUDAD, LA CRISIS COMO OPORTUNIDAD}

Partimos de los procesos de planificación de los años previos, reconociendo y aprovechando su potencial, asumiendo que las gestiones públicas previas son patrimonio ciudadano. Trazamos un planteamiento con los siguientes ejes de desarrollo: sustentabilidad, accesibilidad e integración, desarrollo humano y social y el ordenamiento territorial. Con estos cuatro ejes formamos un proceso de planificación de cerca de quince planes sectoriales y maestros que nos llevó como objetivo macro a sintetizar todo en el plan integral de desarrollo para la región metropolitana. Hicimos un trabajo en cuatro años que nos permitió integrar todos los sistemas de planeación y armar, en un esfuerzo participativo, un plan con visión 2020 para todo el territorio metropolitano. Incluyó procesos como el Plan Maestro de Movilidad, el Plan de Ordenación y manejo de la cuenca, el Plan Maestro de espacios verdes urbanos, el de Desarrollo del turismo, el de Planeación Estratégica y muchos otros, como mecanismos participativos para que la comunidad formule su proyecto de futuro.

Singular valor tuvo el desarrollo de un pacto técnico y político llamado Taller de Ordenamiento Territorial Metropolitano, estrategia con la participación de los alcaldes y líderes técnicos de todos los municipios, para la articulación sencilla de procesos regionales complejos, para que el plan metropolitano reconozca los planes elaborados a escala municipal y simultáneamente estos construyan y asuman el proyecto metropolitano. Es una metodología que plantea la corresponsabilidad, la interacción y la cooperación territorial y política, en un marco de respeto por la autonomía municipal, sustentada en el rigor técnico y la participación, un esquema en el que el respeto y la confianza son la base de trabajo.

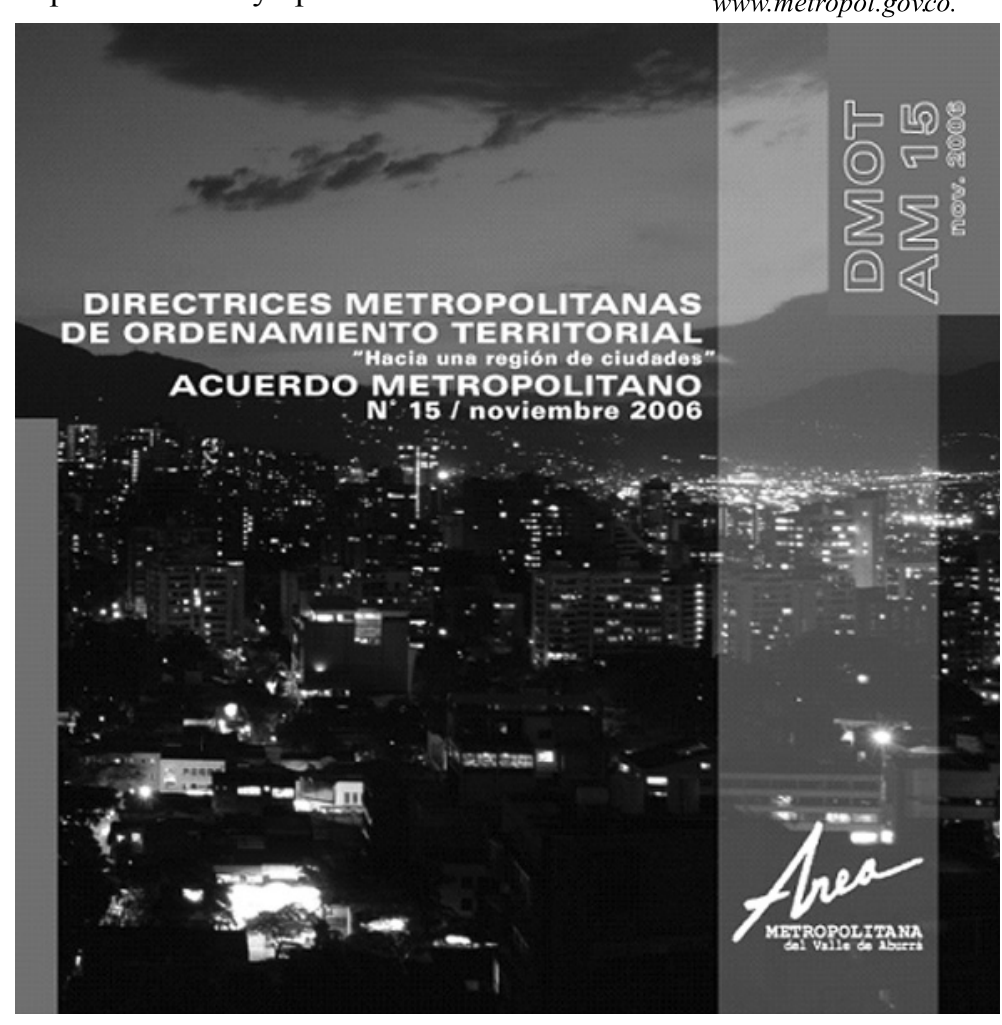

Libro Hacia una región de ciudades, Directrices Metropolitanas de Ordenamiento Territorial, Acuerdo Metropolitano $N^{o} 15$ de 2006.

Fuente:

Fuente: www.metropol.govco 


\section{Jorge Pérez Jaramillo}

Con trabajo permanente, claridades técnicas y argumentales y sin manipulación malintencionada de la información, conseguimos a través del taller que los diez municipios nos pusiéramos de acuerdo (incluido Envigado, que no integra el Área Metropolitana a nivel institucional). Armamos ese pacto de trabajo, y con el liderazgo del Consejo de Planificación y la Junta Metropolitana de Alcaldes - en que además participan el gobernador y dos concejales - hicimos un amplio trabajo de planeación con el que ya en el año 2006 tuvimos el modelo metropolitano de ocupación del territorio, aprobado mediante consenso como norma obligatoriamente general. Este modelo, Hacia una región de ciudades, adoptado como Acuerdo Metropolitano $N .^{\circ} 15$ de 2006, significa que el valle cuenta con una política de ocupación territorial sostenible y competitiva, que se basa en cinco principios - integración, equidad social, sustentabilidad, diversidad, accesibilidad -, y que sin invadir las esferas de cada municipalidad define cómo, a partir del reconocimiento de las condiciones de la base natural, los sistemas de infraestructura, movilidad y equipamientos, es posible construir un esquema de densificación y de poblamiento adecuado, en equilibrio y sostenible.

Otro aspecto central del modelo es la movilidad, en un valle muy estrecho e interconectado que necesita infraestructura de transporte colectivo más sostenible y eficiente, para lo cual desarrollamos no solo el Plan Metropolitano de Movilidad, sino también un esquema de cooperación con el metro de Medellín y la autoridad de transporte.

El modelo de ocupación plantea también elementos para la competitividad con visión prospectiva, esencial para reinsertarnos en la dinámica económica, generadora de empleo, tanto regional como nacional e internacional, e incorpora la accesibilidad plena a los servicios públicos en igualdad de condiciones para todos los habitantes del valle, ya que no sirve una ciudad que brinda servicios públicos a unos sectores y excluye a otros.

Dada la compleja trama de tradiciones y riqueza cultural aún vigente, se consideraron los estudios patrimoniales y las propuestas municipales, así como un concepto renovador del turismo, diversas tradiciones culturales, que demandan tratamientos y consideración sterritorial.

Otro factor que hubo que tomar en cuenta es la dinámica inmobiliaria, que más allá de sus aciertos y problemas, es positiva como energía emprendedora que responde a las necesidades de la comunidad que necesita vivienda y porque genera dinámica económica y empleo, pero queconaspectosnegativos, comolaespeculación del sueloy los riesgos porel manejoabusivo
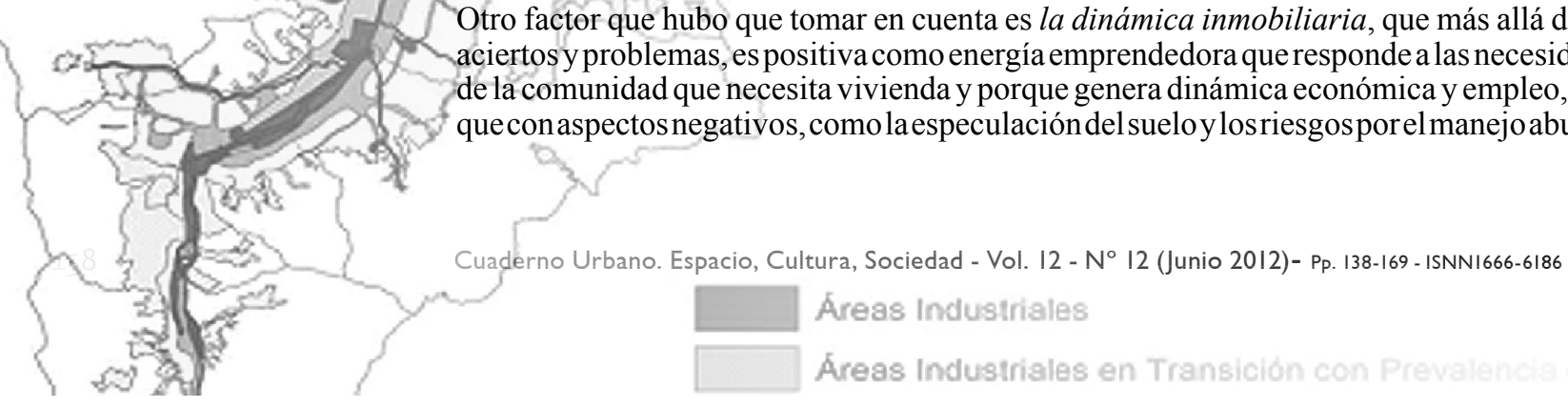

Áreas Industriales

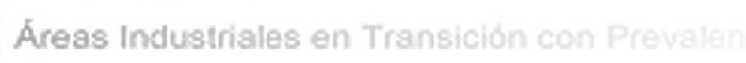




\section{MEDELLÍN METROPOLITANA.}

UNA APROXIMACIÓN A LA CIUDAD, LA CRISIS COMO OPORTUNIDAD

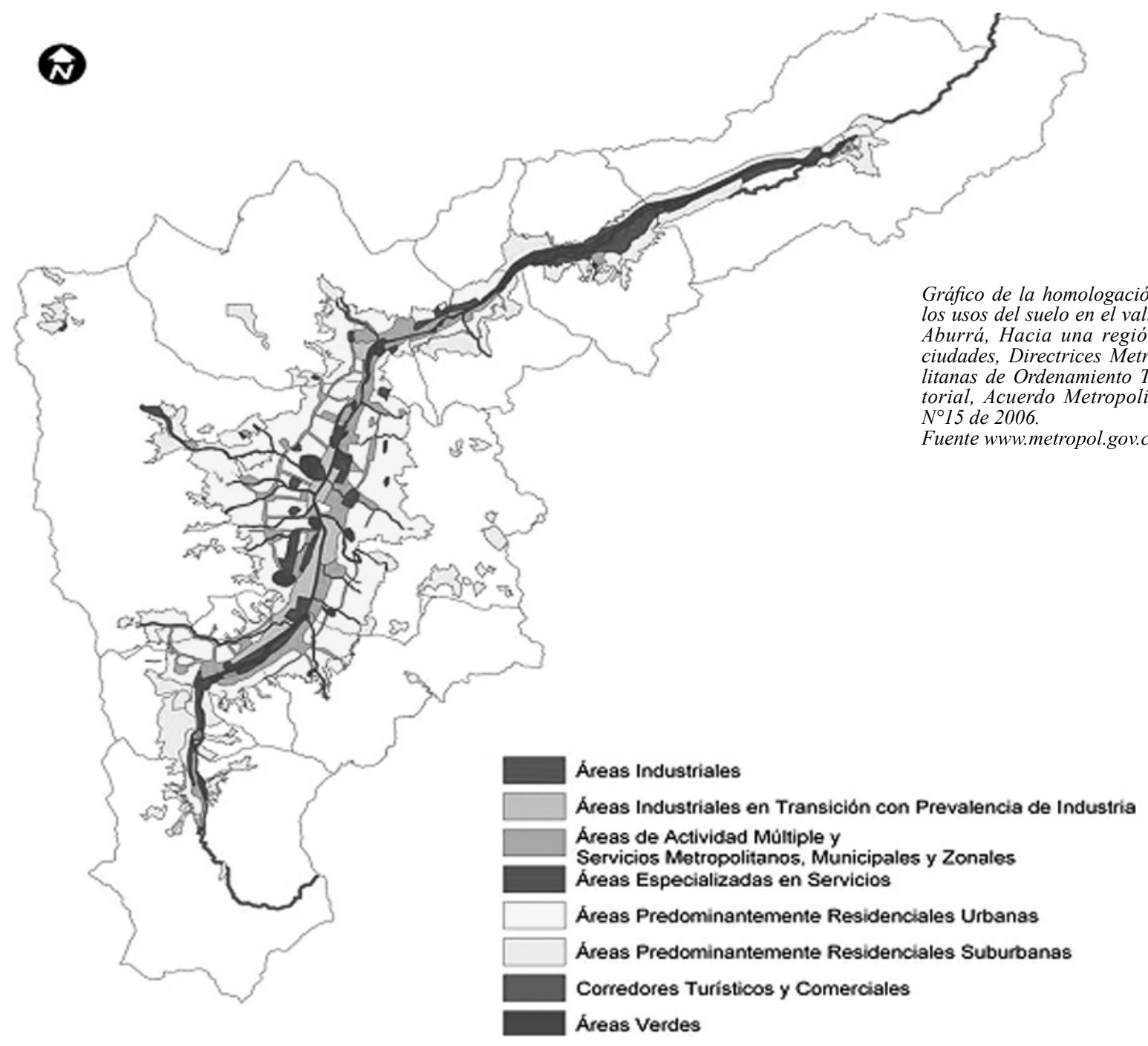

Cuaderno Urbano. Espacio, Cultura, Sociedad - Vol. 12 - No 12 (Junio 20I2)- Pp. 138-169 - ISNNI666-6I86 


\section{Jorge Pérez Jaramillo}

Teníamos que plantear condiciones más precisas, claras y sostenibles, convenientes tanto para los ciudadanos como para los inversionistas, lo cual a mediano y largo plazo resulta más rentable para todos.

La ciudad a escala metropolitana, ante la fuerza expansiva de la urbanización y la fragmentación normativa, requería definir también por consenso metropolitano las cotas máximas de urbanización en las montañas por riesgo natural y por impacto sobre los ecosistemas, y así limitar la expansión de la urbanización sobre las laderas del valle, pues en Medellín la frontera urbana había llegado al límite y urbanizamos áreas estratégicas de la base natural, en condiciones de alto riesgo y con profundo daño paisajístico y ambiental.

Adicionalmente, era necesario consensuar un modelo que, reconociendo la interdependencia y la integración metropolitana, por los flujos y la conurbación, definiera un es-
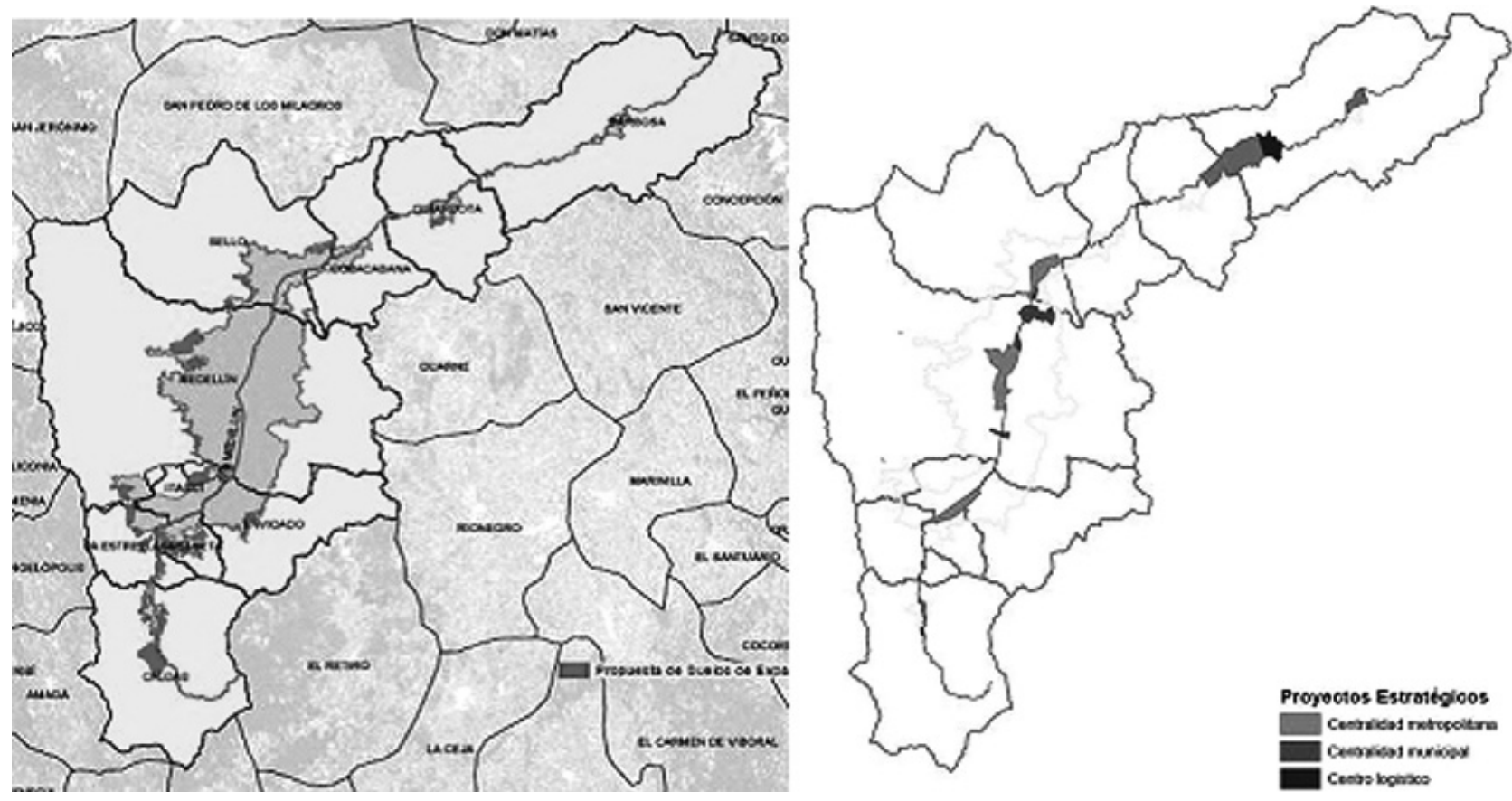


\section{MEDELLÍN METROPOLITANA. UNA APROXIMACIÓN A LA CIUDAD, LA CRISIS COMO OPORTUNIDAD}

quema compacto pero solidario de densificación, con el principio de equilibrado de todos ponen, todos ganan. En la planeación vigente para esos años, en los municipios vecinos se habían destinado las mejores áreas urbanizables para el modelo suburbano de baja densidad, es decir, el modelo de ciudad difusa. En medio de una gran presión urbanizadora, los municipios, de manera individual, habían destinado los suelos más adecuados, mejor dotacuenca, pues lo que ocurre aguas arriba afecta todo lo que hay abajo, es decir, evidenciamos que el territorio no se podía continuar pensando ni gestionándolo desde un solo municipio.

La idea consensuada fue compactar la ciudad en el valle central dejando las densidades más bajas en los extremos norte y sur y los municipios acordaron incorporar nuevos suelos - que aparecen en el mapa con color rojo- para futura expansión urbana, para garantizar el desarrollo de la ciudad. Es un $40 \%$ de hectáreas nuevas, lo que permitirá que para 2030 todavía tengamos suelo para crecimiento urbano en el valle. Esto fue un pacto técnico y político construido desde la base social. dos de infraestructura e integrados a la ciudad, al modelo suburbano con baja densidad.

Con base en los estudios disponibles elaboramos un diagnóstico propositivo, que evidenció que este modelo de ciudad que habíamos planteado a escala metropolitana, con la sumatoria de planes municipales desde el año 2000, no era viable. Por otro lado, la base natural estaba fracturada en normativas contradictorias entre sí, que requerían articulación y concertación. Una cuenca no se puede planificar de manera individual, con argumentos de autonomía o del tipo "el alcalde soy yo", pues la cuenca pasa por los demás municipios, lo mismo que los bosques, la fauna o las quebradas, y por supuesto la sociedad. Había que planificar el sistema de manera concertada en atención a la

Gráfico sintesis del Modelo de ocupación Territorial del Valle de Aburrá. Hacia una región de ciudades, Directrices Metropolitanas de Ordenamiento Territorial, Acuerdo Metropolitano $N^{\circ} 15 / 2006$. Fuente www.metropol.

ON DEL TERRITORIO

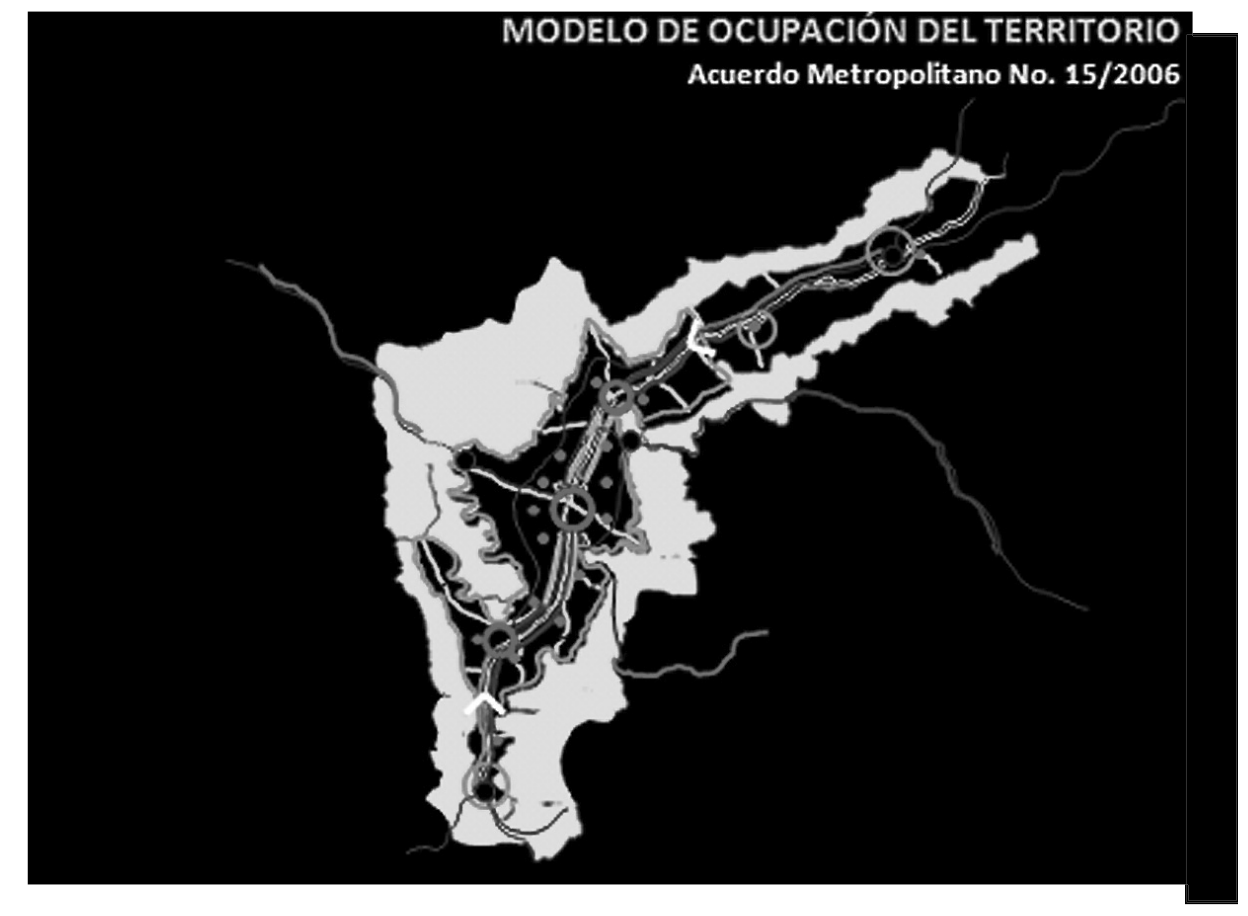




\section{Jorge Pérez Jaramillo}

Metro de Medellín viaducto sobre el sector de la estación Universidad, vecina al Jardín Botánico, al norte del centro de ciudad.

Fuente, Metro de Medellin Ltda.
La síntesis de este modelo con la base natural del corredor del río, todos los sistemas de infraestructura, los centros municipales y las centralidades metropolitanas. Lo que logramos es que hoy todos los municipios definan sus Planes de Ordenamiento Municipal ciñéndose al modelo metropolitano; de hecho ocho de los municipios ya los han ajustado. En conclusión, logramos formular un esquema de reordenamiento territorial que nos permite tener proyectos estratégicos de urbanismo metropolitano, instrumentos de gestión y la concertación de los planes de ordenamiento municipales de manera integral, con visión a largo plazo.

\section{LA IMPORTANCIA DE LOS PROYECTOS ESTRATÉGICOS}

Hay quien dice que el planeamiento es un género literario, una empresa que tiene como resultado grandes centros de documentación en las instituciones. Frecuentemente en nuestro entorno, los planes sirven para dos cosas: para que el consultor que lo hizo tenga un nuevo contrato y aclare cómo se ejecuta y segundo para que no se lleve a cabo porque al alcalde lo eligen para hacer cosas concretas y no para planificar. La pregunta es entonces ¿cómo hacer desarrollo si no planeamos? Entendimos que la planificación debe orientar la acción y que debíamos ser capaces de planificar con cierta simultaneidad. Propusimos proyectos estratégicos que permiten consolidar e implementar el modelo territorial, que generan empleo, que generan riqueza y que les permiten a los alcaldes hacer obras concretas para sus comunidades. Es común que en todo territorio existan proyectos indiscutibles, con alto valor estratégico y pertinencia y se necesita actuar sin aplazar. Los proyectos estratégicos se plantearon a escala metropolitana y municipal, a lo largo de todo el valle, y consolidan las centralidades municipales y metropolitanas. 


\section{MEDELLÍN METROPOLITANA. UNA APROXIMACIÓN A LA CIUDAD, LA CRISIS COMO OPORTUNIDAD}

Desde el año 1985 se habían definido planes que incluían las denominadas centralidades norte a sur, derivadas del plan Hacia la consolidación de la Metrópoli y que nunca pasaron del enunciado. Desde el Taller de Ordenamiento y en consecuencia del Acuerdo Metropolitano convocamos un concurso internacional de urbanismo a mediados de 2007 con un jurado integrado entre otras personas por Manuel de Solá Morales, Francisco Sanín, Carlos Jiménez, Giovanna Spera y Juan C. García, y ahora después de cinco años, estas dos áreas de renovación urbana, superiores cada una a las 300 hectáreas, se han venido desarrollando con los diseños y obras de infraestructura como puentes, viaductos, estaciones de metro y posteriormente áreas inmobiliarias diversas. Son proyectos urbanos que realmente consolidan un modelo de ciudad a largo plazo.

La inclusión pasa también por la infraestructura. De allí la importancia del metro, que le cambió la historia a la ciudad. El metro es un sistema de transporte ejemplar y una empresa eficiente y autosostenible, que no depende de los presupuestos públicos para su operación y funciona con autonomía presupuestaria. Recientemente, la empresa Metro ha implementado el Metrocable, y ahora está en camino el desarrollo del sistema de tranvía y el de buses articulados BTR, lo que nos ofrece un panorama futuro de ciudad con altos niveles de integración y accesibilidad, una apuesta por la sostenibilidad territorial.

Lo que es importante destacar de la experiencia de gestión del metro es que el transporte es mucho más que un recurso para ir de un lugar a otro. En el caso del Metrocable, se convirtió en un esquema de integración ciudadana, pues las comunidades de estos barrios marginados comenzaron a implicarse y unirse, y una vez conectadas a la ciudad pasaron de ser simplemente habitantes a ser ciudadanos, a ser parte integral de Medellín.

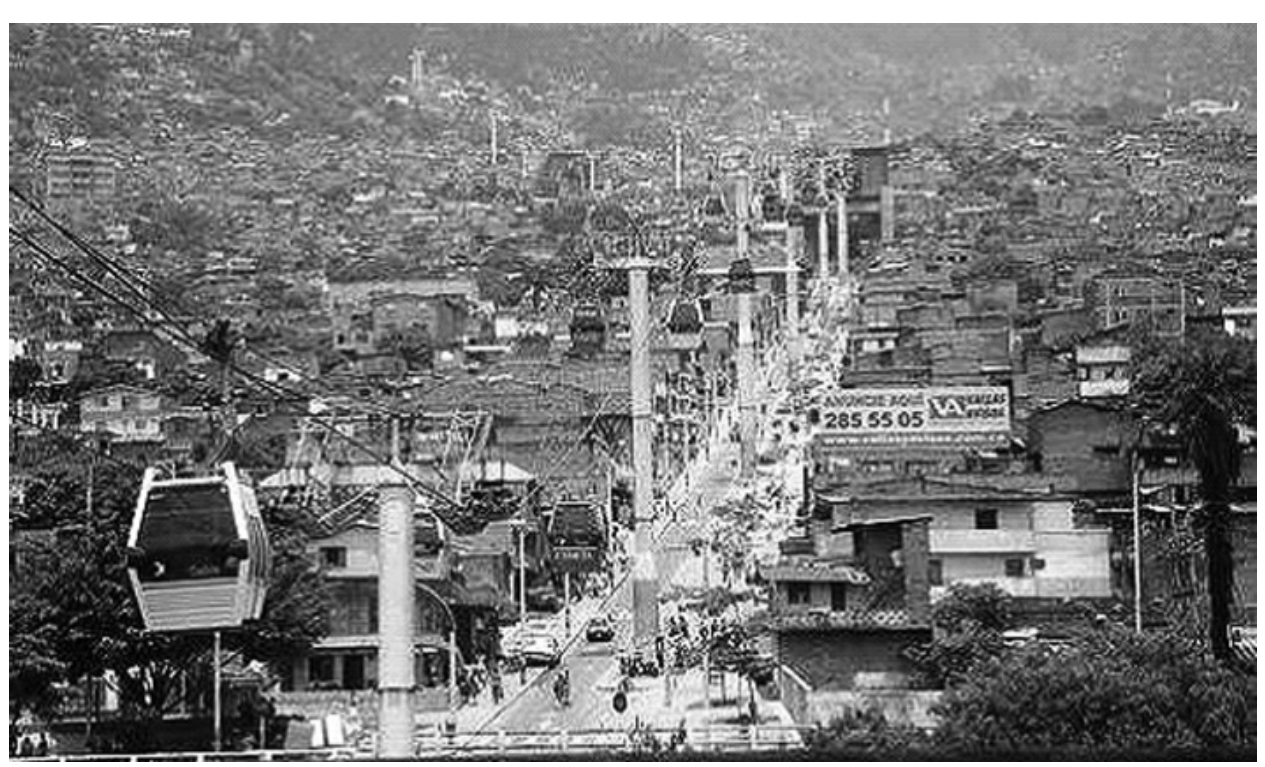




\section{Jorge Pérez Jaramillo}

Lo esencial de todo esto es que la planificación y el modelo de ciudad en cuanto a proyectos como estos permite que aquella funcione de manera más efectiva, pues cuando se planifican los corredores de transporte masivo también se valorizan todos los corredores inmobiliarios que hay alrededor. Es decir que hay una transferencia de valor de lo público a los propietarios privados. Esto quiere decir que la inversión pública puede recuperarse por la vía de la plusvalía. Hoy los transportes que estamos construyendo consideran estos conceptos.

\section{MEDELLÍN, EN EL CAMINO DE LA ESPERANZA}

Como se ha mencionado antes, el conjunto de nuestra sociedad, inspirada por un cierto instinto de supervivencia ante la desesperanza, desarrolló un intenso proceso de autocrítica y revisión colectiva, una toma de conciencia sobre errores acumulados, y construyó acuerdos sobre los grandes problemas por resolver, una especie de pacto social, probablemente inconsciente e incompleto pero potente, que permitió un relevo generacional en

Parque de los Deseos, arquitecto Felipe Uribe de $B$. 2003.

Fuente: Foto Sergio Gómez. el liderazgo político y social, con nuevas ideas y compromisos y voluntad de emprender un nuevo camino.

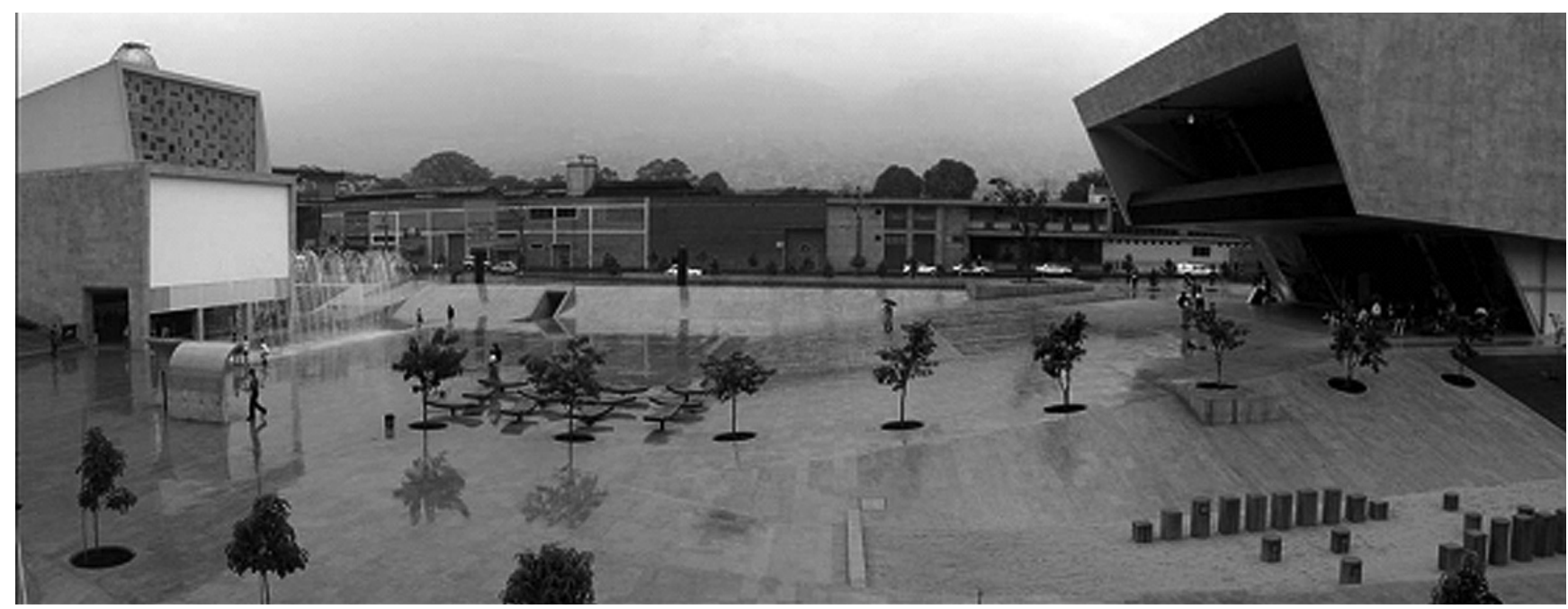




\section{MEDELLÍN METROPOLITANA. UNA APROXIMACIÓN A LA CIUDAD, LA CRISIS COMO OPORTUNIDAD}

Transformar la ciudad fue el objetivo. Desde entonces, con varios esquemas y amplia participación ciudadana, se gestó un proyecto cívico que hoy es una realidad: Medellín metropolitana, una ciudad en camino de transformación.

Las universidades tuvieron un papel trascendente. Con investigación y experimentación gestaron una masa crítica de profesionales y arquitectos, enfocados en los problemas urbanos, quienes sumados a procesos políticos cívicos plantearon ideas y conocimientos que han contribuido a hacer de Medellín un intenso laboratorio urbano. Desde 1998, cuando se construyó el Parque de los Pies Descalzos por parte del Laboratorio de Arquitectura y Urbanismo de la Facultad de Arquitectura de la Universidad Pontificia Bolivariana (Spera, Vélez y Uribe, arquitectos en el gobierno del alcalde J. Gómez), se emprendió un camino de intervenciones urbanas y proyectos de equipamientos y espacios públicos para promover integración, equidad y dignidad para la comunidad. Obras como el Museo de Antioquia-Fernando Botero (B. Jaramillo, E. Cera y otros 1999-2000) del alcalde J. Gómez o el Metrocable Santo Domingo, la Biblioteca EPM y el Parque de los Deseos EPM (F. Uribe, arquitecto) promovidos por el alcalde L. Pérez entre 2001-2003 son testimonio de estos emprendimientos.

La construcción de infraestructuras de transporte colectivo, espacios públicos y diversos equipamientos sociales, que

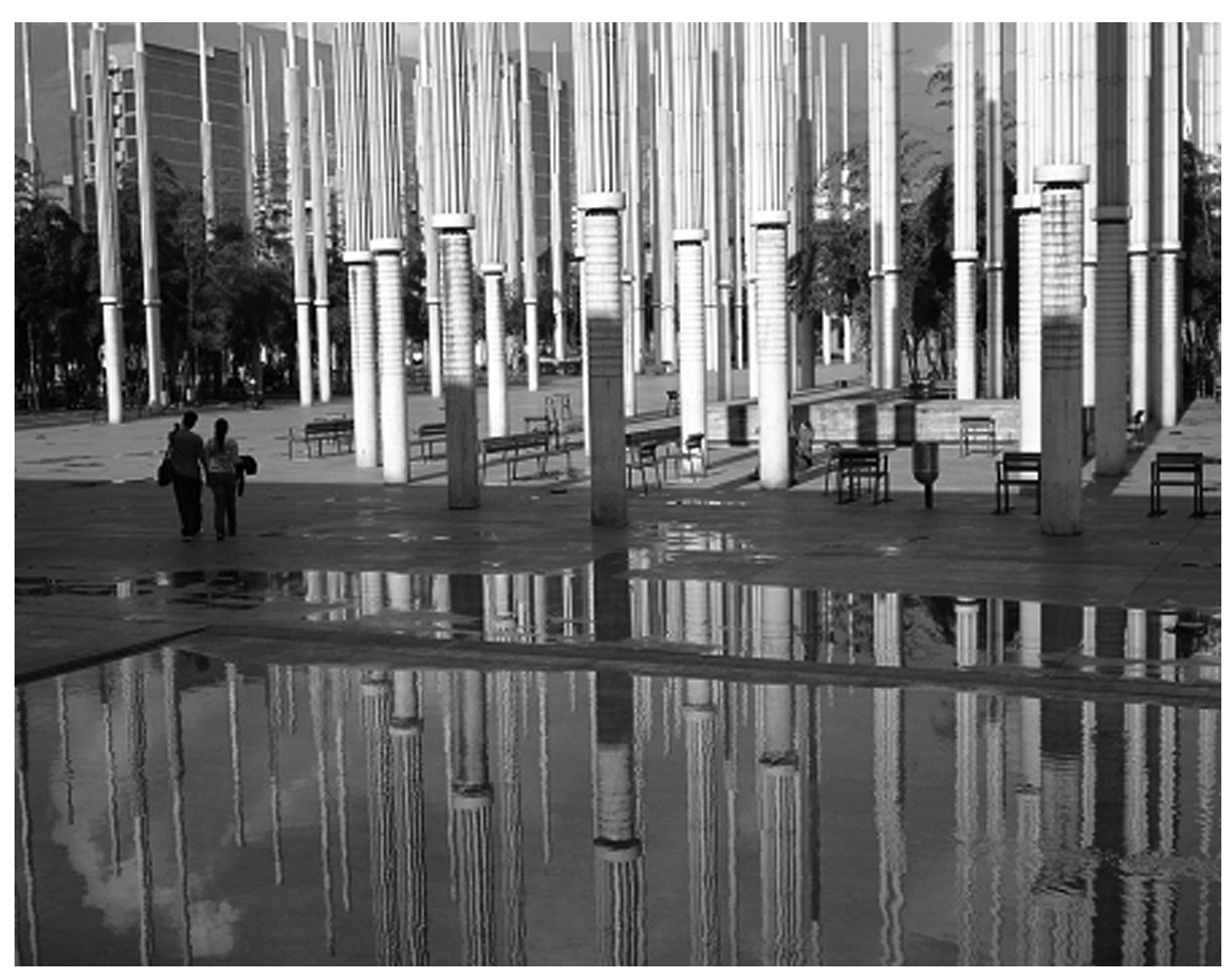

Plaza de Cisneros, arquitectos Juan Manuel Peláez y Luis Fernando Peláez (escultor), 2002-2003.

Fuente: Foto del autor. 


\section{Jorge Pérez Jaramillo}

Colegio Santo Domingo Derka, Barrio Santo Domingo Savio, 3005-07. Carlos Pardo B. Arquitecto, Obranegra arquitectos.

Fuente: Foto Cortesia del autor del proyecto. complementó múltiples procesos de diálogo, emprendimiento social, fortalecimiento de instituciones del Estado y especialmente de las autoridades de seguridad y justicia, así como la búsqueda de nuevos escenarios para el desarrollo económico han contribuido a una superación parcial de los problemas más críticos, que si bien persisten, evidencian un avance singular y esperanzador para Medellín.

Como describí antes, uno de los elementos clave del cambio fue el llamado Movimiento Ciudadano, un proyecto de partido político cívico en el que confluyeron diversos líderes, quienes cansados de las formas de la política tradicional, con sus vicios y corrupción, así como de la falta de oportunidades y liderazgo para superar la crisis, buscaron una alternativa política para liderar la gestión pública. Tras dos intentos electorales, llegó al gobierno municipal 2004-08 del alcalde Sergio Fajardo un proceso que marcará un momento de inflexión en la gestión pública local y en el desarrollo de la ciudad.

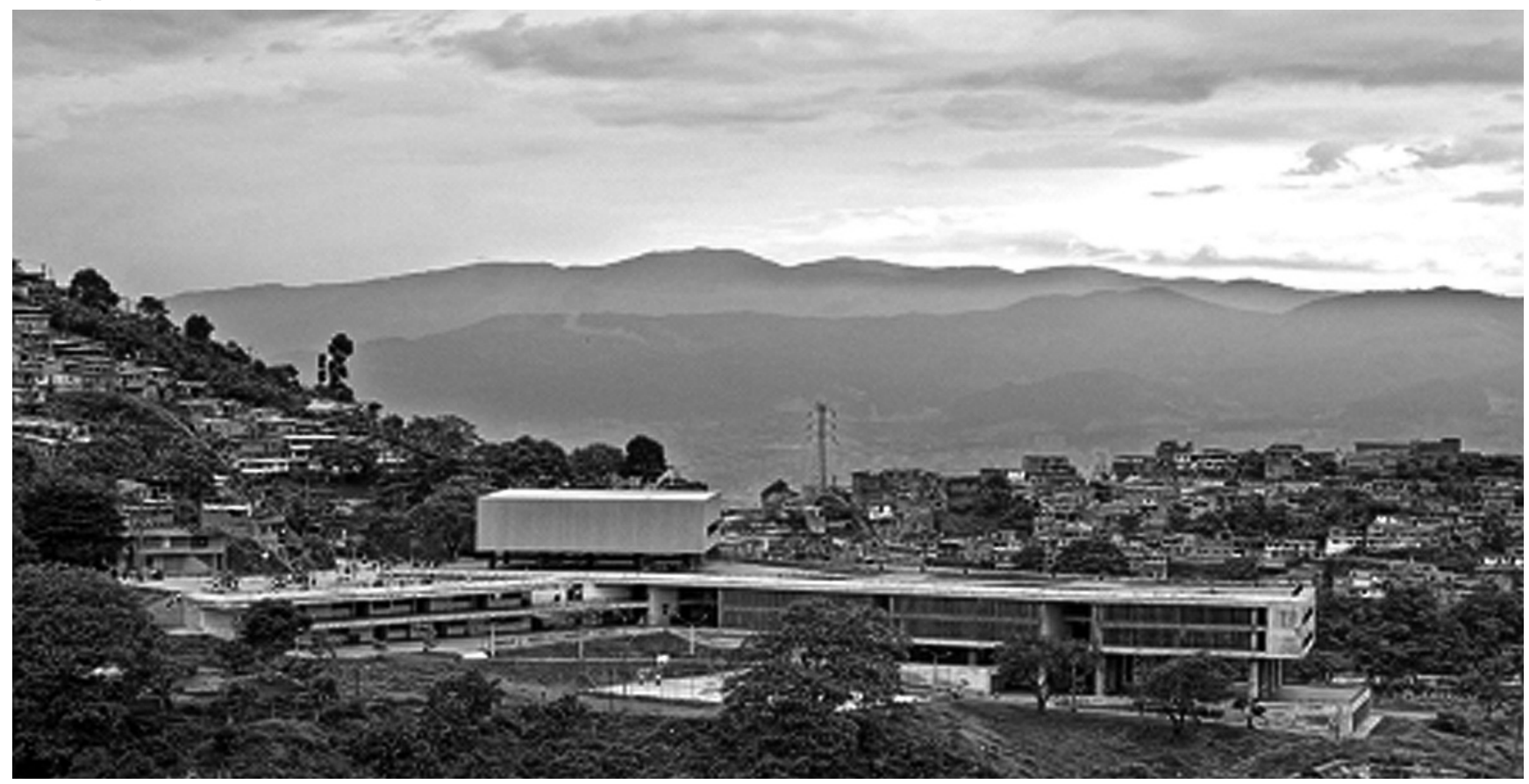




\section{MEDELLÍN METROPOLITANA. UNA APROXIMACIÓN A LA CIUDAD, LA CRISIS COMO OPORTUNIDAD}

Su gestión, con el lema "Medellín la más Educada", lideró equipos técnicos ampliamente conocedores de la ciudad y destinó la mayoría del presupuesto de inversiones a los barrios con menor índice de desarrollo humano, marcó un momento de cambio y desarrolló intervenciones urbanísticas de indudable calidad, diversidad y magnitud. Muchas obras, caracterizadas por su buena arquitectura, llevaron soluciones espaciales e inclusión social a comunidades hasta entonces marginadas, contribuyendo a elevar las condiciones de vida y a promover nuevos escenarios de convivencia y ciudadanía. La gestión adelantada durante su gobierno, entre los años 2004-2007, con una inmensa acción sobre el urbanismo, es un emblema del Medellín de hoy y marcó un camino que la ciudad ha continuado, con los sucesivos gobiernos de Alonso Salazar 2008-11 y el actual, a cargo de Aníbal Gaviria.

Figura 19. Escenarios Deportivos, coliseos Unidad Deportiva Atanasio Girardot, arquitectos planb Felipe Mesa + Giancarlo Mazzant, 2008-1i.

Fuente: Dibujo del concurso cortesía de los autores del proyecto.

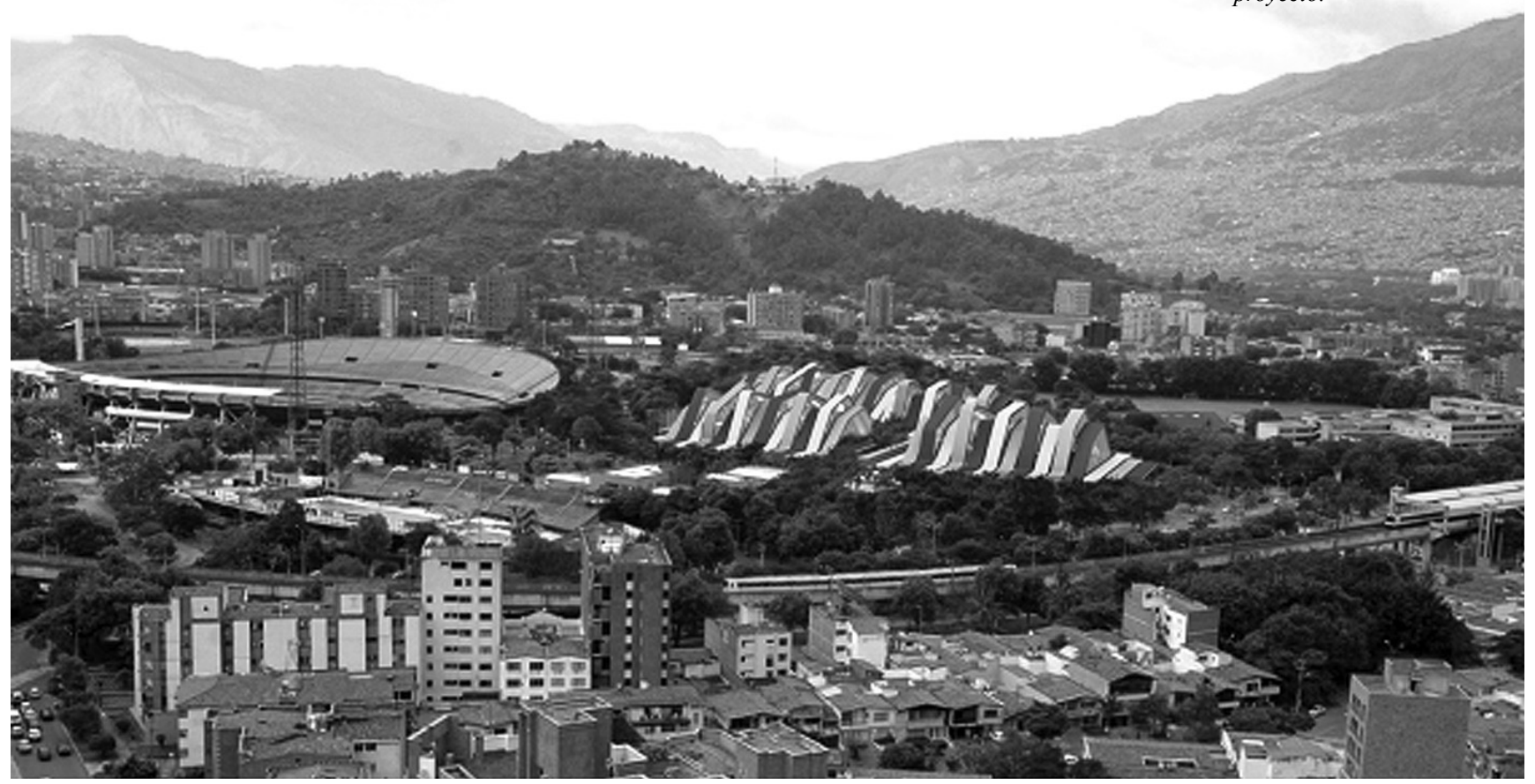




\section{Jorge Pérez Jaramillo}

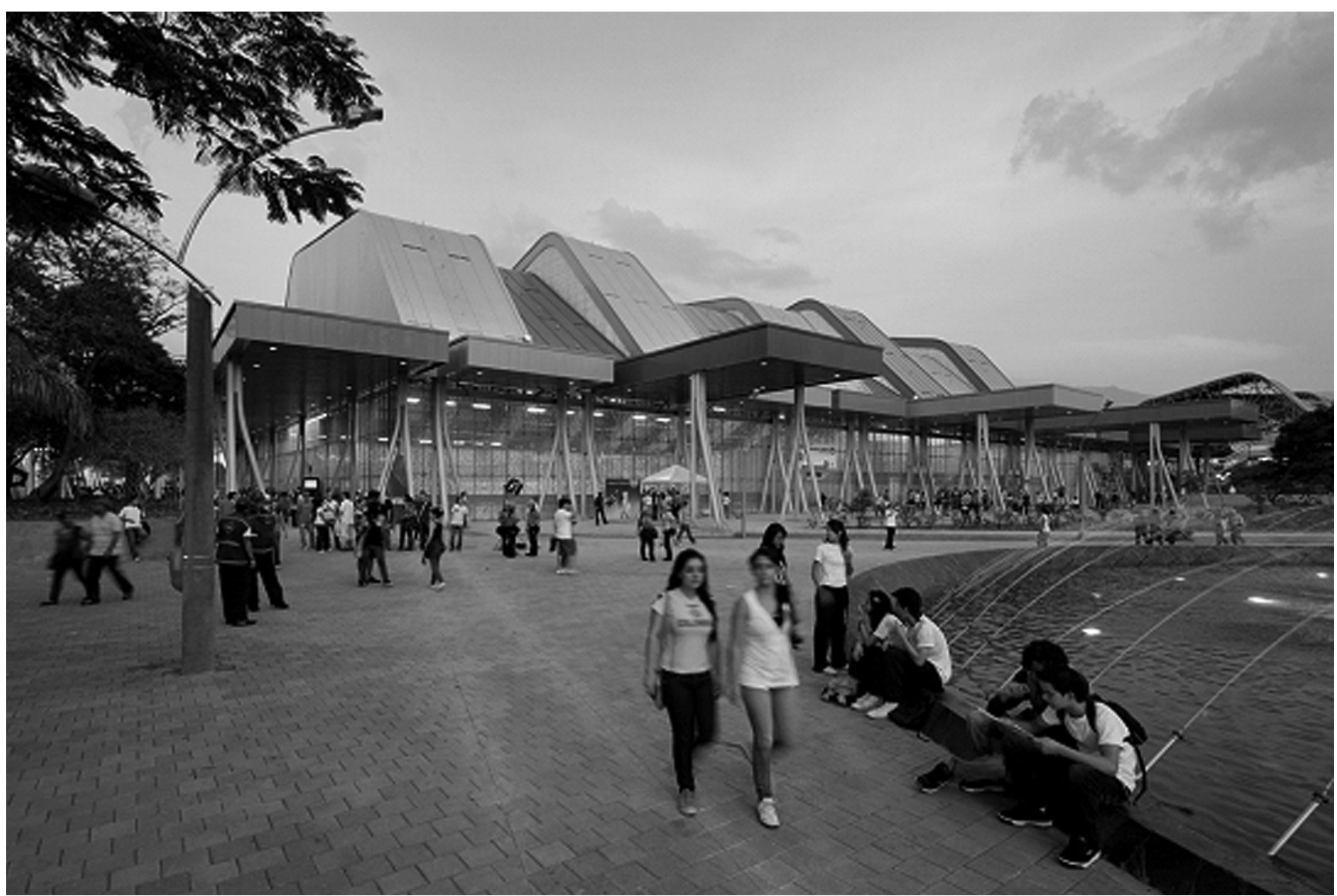

Escenarios Deportivos, coliseos Unidad Deportiva Atanasio Girardot, arquitectos planb Felipe Mesa + Giancarlo Mazzant, 2008-1i.

Fuente: Foto cortesía de los autores del proyecto.
Nuestra sociedad aún tiene inmensos retos. Seguimos trabajando para superar nuestra complejidad, con dificultades como delincuencia organizada, tasas de exclusión e inequidad, insuficiencia de oportunidades, corrupción y desempleo, así como la mala política generalizada en el Estado colombiano, que en medio de muchos logros, aún demandarán años de trabajo. 


\section{MEDELLÍN METROPOLITANA. UNA APROXIMACIÓN A LA CIUDAD, LA CRISIS COMO OPORTUNIDAD}

Los retos urbanos están vigentes. La región metropolitana reclama amplios niveles de concertación y trabajo conjunto, articulación que dará camino a la sostenibilidad. Esperamos que los actuales gobiernos de Medellín y Antioquia, liderados por Aníbal Gaviria y Sergio Fajardo - quienes hoy alternan en los cargos que en el pasado compartieron gobernación y alcaldía de Medellín-, sean capaces de consolidar los procesos trazados de integración regional.

Debemos continuar trabajando en fomentar ideales democráticos y participativos, que consigan equidad, inclusión y opciones de futuro para todos. Medellín metropolitana seguirá como un rico laboratorio para la complejidad urbana del siglo XXI.

Este documento es producto del aprendizaje derivado de trabajos como la gestación del Laboratorio de Arquitectura y Urbanismo LAUR / FAUPB con Giovanna Spera en 1997, la participación en la Junta Técnica del Plan Estratégico Medellín y el Valle de Aburrá 1998-2015 Alcaldía de Medellín/PNUD (1995-98) y el Proyecto CITIES Medellín Metropolitana, desarrollado con la Fundación Metrópoli y FAUPB (1998-2001). La gestión en la Subdirección de Planeación del Área Metropolitana del Valle de Aburrá y el Taller de Ordenamiento Territorial del Valle de Aburrá (2004-2008), un instrumento novedoso para el trabajo asociativo en la gestión territorial, mecanismo técnico para la coordinación y articulación del territorio y los municipios. El taller fue inspirado y coordinado por Sergio Bustamante Pérez, Jorge Pérez Jaramillo y Juan Manuel Patiño, y liderado conjuntamente con Diana Catalina Álvarez, Giovanna Spera, Ana Isabel Zea, Juan Carlos García, Carlos Gómez Jaramillo, con el soporte de un amplio grupo de profesionales de la institución y la región. Con algunas personas que integran este grupo hemos creado el Instituto de Estudios Metropolitanos IEMR asociado a la Universidad Pontificia Bolivariana en Medellín. 



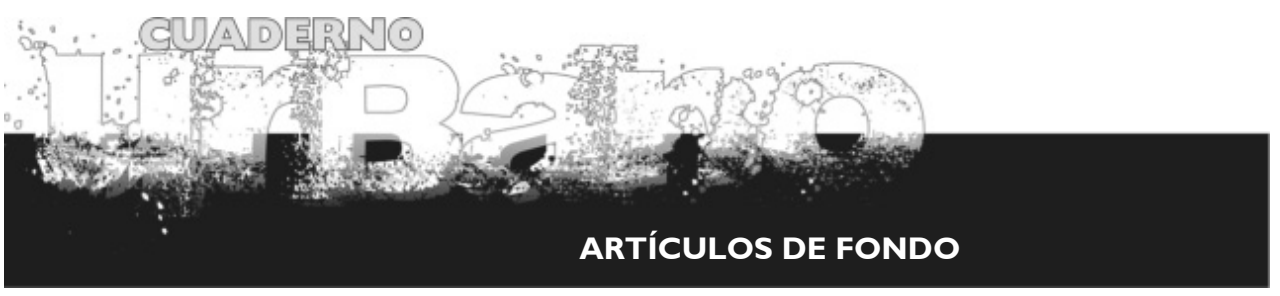


